\title{
Local religious beliefs and insurance companies' risk-taking behaviour
}

\author{
Thomas R. Berry-Stölzle ${ }^{1}$ Jianren $\mathrm{Xu}^{2}$ (1)
}

Received: 1 June 2020 / Accepted: 11 February 2021 / Published online: 6 April 2021

(C) The Geneva Association 2021

\begin{abstract}
We empirically examine the effect of local religious beliefs on the risk-taking behaviour of U.S. life insurers headquartered in that region. We distinguish between insurers that predominantly write annuities and insurers that predominantly write life insurance policies; the annuity business is relatively riskier than writing life insurance. Insurers headquartered in high-Catholic or low-Protestant areas are more likely to be annuity writers. Annuity writers located in high-Catholic or low-Protestant areas invest more in risky assets and exhibit higher investment return volatilities, as well as a higher volatility of their return on assets. Overall, our results suggest that local culture has significant influences on life insurers' behaviour.
\end{abstract}

Keywords Risk-taking · Local religious beliefs · Insurance companies

\section{Introduction}

How much risk an insurance company takes directly impacts the quality of its products from the point of view of its clients (Epermanis and Harrington 2006; Eling and Schmit 2012). That is why rating agencies and regulators closely monitor insurance companies' risk-taking and capitalisation levels. That is also why there is a growing body of literature on insurance companies' risk-taking choices (e.g. Fields et al. 2012; Ho et al. 2013; Mankaï and Belgacem 2016; Milidonis et al. 2019). Another growing body of literature focuses on behavioural or cultural aspects of business decisions. While most behavioural biases and local cultures are hard to observe and

Jianren Xu

jianren.xu@unt.edu

Thomas R. Berry-Stölzle

thomas-berry@uiowa.edu

1 Henry B. Tippie College of Business, University of Iowa, 108 John Pappajohn Business Bldg, Iowa, IA 52242-1994, USA

2 G. Brint Ryan College of Business, University of North Texas, 1155 Union Circle \#305339, Denton, TX 76203-5017, USA 
measure, religious beliefs can be captured with a relatively simple measure: affiliation with a church. Hence, a number of studies empirically examine the effects of local religious beliefs on business decisions of firms headquartered in that region. There is evidence that local religious beliefs indeed impact corporate investments (e.g. Hilary and Hui 2009; Kumar et al. 2011), debt financing (Cai 2019), earnings management (Dyreng et al. 2010), tax avoidance (McGuire et al. 2012), accounting conservatism (Ma et al. 2020) and manager option grants and compensation packages (Grullon et al. 2010), as well as investment decisions of mutual funds (Shu et al. 2012) and hedge funds (Gao et al. 2017). However, limited evidence exists on the behavioural or cultural aspects of risk-taking decisions in financial institutions in general and insurance companies in particular. ${ }^{1}$

The goal of our research is to examine whether local culture effects insurance companies' risk-taking. To answer this question, we focus on local religious beliefs, for which we can obtain a quantifiable measure. Since there are substantial differences between the different segments of the insurance industry, we focus on life insurance companies in our analysis. We view risk-taking of life insurance companies as an important research question for the following reasons. First, life insurance companies rely on investment income to fund life insurance payouts and annuity benefits. Excessive investment risk-taking and resulting investment losses during capital market downturns can lead life insurance companies into financial distress. Thus, the current market downturn caused by a slowdown of economic activity due to the COVID-19 health crisis is especially challenging for life insurance companies and their investments. The recent financial crisis created similar challenges for life insurers. In the U.S., two life insurers even received funds from the Troubled Asset Relief Program (TARP) initiated by the U.S. Treasury to stabilise financial institutions. ${ }^{2}$ Second, life insurance companies are major institutional investors in capital markets. Understanding how large players invest is of interest to all other market participants. Given prior evidence that religion impacts corporate investments, we expect local religious beliefs to have noticeable effects on life insurers and their investments. Local religious beliefs are one important component of local culture. Thus, our research provides evidence on the degree to which local culture and its norms influence insurance company decisions.

There are two theoretical arguments on why insurers' risk-taking behaviour may be impacted by local culture. Social identity theories (e.g. Tajfel 1978; Turner and Reynolds 2010) suggest that people identify themselves with relevant social groups and derive utility from conforming to group norms. Therefore, individuals might adjust their behaviour to fit with their social environment. Further, managers and employees in the labour market might choose to join a firm headquartered in a

\footnotetext{
1 One notable exception is Adhikari and Agrawal's (2016) study. They examine the impact of local religiosity measured with the total religiosity ratio (the proportion of religious adherents in the population) on risk-taking of banks. We study the impact of local religious beliefs measured with the Catholic ratio, the Protestant ratio and the Catholic-to-Protestant ratio on risk-taking of insurance companies.

2 The two life insurance companies that received funds from TARP were The Hartford and Lincoln National. They obtained USD 3.4 billion and USD 950 million, respectively (Source: SNL Financial's TARP Participant List).
} 
region that has a culture they feel comfortable with (e.g. Schneider 1987; Hilary and Hui 2009).

Prior literature documents a strong and robust relationship between religious beliefs and risk attitudes of both individuals and firms. Individual Protestants tend to exhibit more risk-aversion than individual Catholics (e.g. Halek and Eisenhauer 2001; Kumar 2009; Noussair et al. 2013). Institutional investors located in regions with a high Catholic-to-Protestant population ratio tend to hold more risky stocks and have more risky corporate policies (e.g. Kumar et al. 2011; Schneider and Spalt 2016). Similarly, Shu et al. (2012) document that mutual funds' risk-taking is impacted by local religious beliefs; mutual funds located in high-Catholic or lowProtestant ratio counties have a higher fund return volatility.

Although insurers' risk-taking behaviour may be impacted by local religious beliefs, market competition and economic incentives may diminish or even eliminate these cultural effects (Shu et al. 2012 1779). Especially in the highly regulated insurance industry, where demand is sensitive to insurers' default risk (e.g. Doherty and Schlesinger 1990; Cummins and Danzon 1997) and regulators have the power to liquidate failing companies quickly (Cummins et al. 1995), market pressure may counterbalance any cultural influence on risk-taking decisions. Thus, whether local culture impacts insurers' risk-taking behaviour is an empirical question.

In this paper, we empirically investigate the influence of local religious beliefs on insurers' risk-taking behaviour. We use data of U.S. single unaffiliated life insurance companies and focus on the time period leading up to and covering the recent financial crisis. Unlike insurance groups, single unaffiliated insurers with a single geographic location present a great laboratory to examine the effect of local culture on insurer risk-taking in a clear-cut manner. Focusing on the time period surrounding the recent financial crisis ensures that differences in investment risk-taking become more easily measurable as those differences result in decreased asset valuations and realised or unrealised investment losses. Using data from life insurers from 2001 to 2010, we examine the impact of county-level Catholic, Protestant or Catholicto-Protestant ratios on the risk-taking behaviour of insurers headquartered in that county. ${ }^{3}$ The Catholic (Protestant) ratio is measured as the fraction of the population in a particular county that are Catholics (Protestants). The Catholic-to-Protestant ratio is defined as the Catholic ratio divided by the Protestant ratio.

We find that insurers that predominantly write annuities (annuity writers) are more common in regions with a larger fraction of Catholics in the population or

\footnotetext{
3 In our study, we focus on Catholics and Protestants for the following reasons. First, Catholics and Protestants are the two largest religious denominations in the U.S. The recent American Religion Data Archive (ARDA) surveys do provide data on the numbers of adherents of other religious bodies; however, their fractions of adherents are so small that an empirical analysis of these religious beliefs may not produce reliable results. For example, the fraction of Jewish (Islamic, Orthodox) adherents to total county population has a mean of $0.277 \%(0.087 \%, 0.095 \%)$ and a median of $0 \%(0 \%, 0 \%)$ across the U.S. in 2000, respectively. In addition, Catholics and Protestants share many similarities and relatively limited differences (compared with Catholics vs. Muslims for instance). From our point of view, the differences in corporate risk-taking are the only obvious testable implications in the context of financial institutions. See Benjamin et al. (2016) for detailed dissimilarities between Catholics and Protestants.
} 
a lower fraction of Protestants in the population. ${ }^{4}$ Annuity writers are more risky than other types of life and health insurers as a result of their more volatile earnings and capitalisation (Berry-Stölzle et al. 2014). This finding supports the notion that risky business is more accepted in high-Catholic-ratio or low-Protestant-ratio areas. In other words, our result is consistent with the theory that Catholics (Protestants) have a culture that is more (less) tolerant towards risk.

While most of the prior literature on insurer risk-taking focuses only on one risk proxy (Ho et al. 2013), we employ three different risk measures to capture insurers' risk-taking activities. ${ }^{5}$ Due to the systematic differences in risks taken between insurers that predominately write annuity business (annuity writers/providers) and those that predominately write life business (life writers/providers) (Berry-Stölzle et al. 2014), we separate the analyses on asset risk, investment risk and total risk-taking decisions for these two major types of insurers with different business focuses. We document that annuity writers located in higher Catholic-to-Protestant ratio, higher Catholic ratio, or lower Protestant ratio counties take more asset risk and total risk. We also find that annuity writers' investment risk is significantly positively associated with local Catholic-to-Protestant ratio and negatively associated with Protestant ratio.

In addition to the main findings, we show evidence that insurers located in higher Catholic-to-Protestant ratio areas tend to have a longer history, larger net admitted assets, lower capital-to-assets ratio and less reinsurance usage. In high Catholic-toProtestant ratio areas, there are more insurance company headquarters, less stock insurers, more annuity providers, less life providers and less publicly-traded companies. With regard to lines of business, insurers located in high Catholic-to-Protestant ratio areas tend to write more annuities, less life insurance, less accident and health business and more other lines of business.

The literature on the demand for insurance highlights that individual risk aversion, bequest motives (e.g. Bernheim 1991) and religious beliefs influence insurance purchasing decisions. However, we do not expect religion-induced demandside effects to drive our main results for the following reasons. First, life insurance companies have a large number of individual clients and even small life insurance companies service a relatively large geographic area and generate premium revenue from different geographic regions. ${ }^{6}$ Since religious beliefs are quite heterogeneous

\footnotetext{
${ }^{4}$ Insurers that predominantly write annuities are defined as insurers with over $2 / 3$ of net premiums written in ordinary individual annuity and group annuity business. They are referred to as 'annuity writers/ providers' throughout the paper. Insurers that predominantly write life business are defined as insurers with over $2 / 3$ of net premiums written in industrial life, ordinary life, group life and credit life insurance. They are referred to as 'life writers/providers' throughout the paper.

5 We study asset risk, investment risk and total risk but not underwriting risk in this paper. Underwriting risk is usually captured by the volatility of loss ratio and is commonly investigated in the propertycasualty (P\&C) insurance industry (Lamm-Tennant and Starks 1993). In the life insurance industry, an equivalent to the $\mathrm{P} \& \mathrm{C}$ loss ratio would be the ratio of life insurance output, incurred benefits (Berger et al. 2000) to premiums earned. This ratio is relatively stable and the loss experience for life insurers is relatively smooth due to the stable mortality rate and low exposure to catastrophic losses.

${ }^{6}$ All life insurance companies in our sample sell, on average, life insurance policies and annuities in 22 different states and the subsample of annuity writers sells their products, on average, in 26.6 different states.
} 
across geographic areas in the U.S., it would not be an easy task for a company to determine which religious beliefs the company should cater to. Second, many individual policyholders are protected by state guaranty funds if their insurance carrier goes bankrupt. Any policyholder with such a protection should be insensitive to insurance companies' risk-taking (Lee et al. 1997). We therefore argue that the effect of local religious beliefs at the headquarters' location should be more pronounced than any potential demand-side effects, which we view as second-order effects, and that local religiosity at the headquarters' location is not a proxy for religion-induced demand-side effects. In our empirical model, we control for population demographics that we expect to be correlated with demand for annuities and other life insurance products.

Our study contributes to the literature in several ways. First, to the best of our knowledge, this research is the first to focus on the effects of religious beliefs, an important component of local culture, on the risk-taking decisions of insurance companies. Second, most prior studies on the effects of local religious beliefs only focus on publicly-traded stock companies. We extend the literature by studying the impact of local religious beliefs on both private and public firms, as well as different organisational forms. It is interesting to see that the conformity of firm behaviour with local culture still holds in private firms and firms with other organisational forms. Finally, whereas prior studies on risk-taking of insurance companies concentrate on managerial ability, corporate governance and firm characteristics, we make an important contribution to the insurance literature by providing the first explanation from a local culture perspective.

Of course, religious beliefs are only one part of local culture. Especially in international studies across different countries and continents, other cultural differences may be more pronounced than differences in religious beliefs. Hofstede (1984) developed a framework to describe national cultures; his framework consists of four major components and religious beliefs are not one of them. In their international experimental study, L'Haridon and Vieider (2019) fail to find significant differences in risk preferences between Catholics and Protestants. We do not claim that the differences between Catholics and Protestants we observe in the U.S. exist in the same way in other countries and other cultural environments. We simply use the different religious beliefs in the U.S. in our analysis because they are an easy way to quantify differences in local culture. We view our results as evidence that local culture influences life insurance companies' decisions, and especially life insurance companies' risk-taking decisions.

\section{Conceptual background and hypothesis development}

\section{Theories of relation between religiosity and risk-taking at the individual level}

Economists and sociologists have disclosed a strong relationship between religion and economic behaviour at both macro and micro levels. Prior research provides evidence that religion plays an important role in government performance, creditor protection, economic development and institutional structure (e.g. La Porta 
et al. 1999; Stulz and Williamson 2003; Barro and McCleary 2003; Guiso et al. 2006). On the other hand, recent financial studies have documented the association between religion and corporate investment, accounting policies, managerial decisions and financial market outcomes (e.g. Hilary and Hui 2009; Dyreng et al. 2010; McGuire et al. 2012; Kumar et al. 2011). As suggested by Iannaccone (1998) and Noussair et al. (2013), risk attitudes embedded in different religious beliefs could be one crucial mechanism that links religion and economic behaviour. Hence, it is important to recognise and examine the diverging risk attitudes of different religious beliefs (e.g. Catholics vs. Protestants) to gain insight into how religion shapes economic outcomes.

The distinct risk attitudes between Catholics and Protestants may originate from their different viewpoints towards gambling (e.g. Kumar et al. 2011; Benjamin et al. 2016). While Catholicism and Protestantism share many similar sacred texts, the moral teachings with regard to gambling are divergent (e.g. Halek and Eisenhauer 2001; Shu et al. 2012). Bell (1974) documents that Protestant moral condemnation of gambling is prevalent in the U.S., which is not the case for Catholicism. Strong Protestant moral resistance to gambling and lotteries can be traced back to the inception of the Protestant movement, and it has been a fundamental doctrine of Protestantism. As a result, gambling is deemed a sinful and reprehensible activity by typical Protestants (e.g. Starkey 1964; Ellison and Nybroten 1999). In fact, the Southern Baptists, the largest Protestant denomination, have a particularly strident opposition towards gambling (Kumar et al. 2011). On the contrary, Catholicism preserves a tolerant view on, and sometimes even promotes, gambling. In many Catholic parishes, bingo and charitable gaming events based on gambling have been used frequently to raise funds (Hoffman 2000). Prior literature has provided evidence that dominant local religious beliefs indeed drive the popularity of state lotteries (e.g. Berry and Berry 1990; Ellison and Nybroten 1999). A number of recent studies also empirically show that Catholic and Protestant norms towards gambling extend to financial decisions (e.g. Kumar 2009; Doran et al. 2012). Gambling involves either financial gains or losses. From this perspective, gambling is analogous to taking financial risk. Since Catholics are more tolerant to gambling than Protestants, we would expect Catholics to be more open towards risk-taking or less risk-averse than Protestants.

In addition, Noussair et al. (2013) provide evidence that the correlation between religion and risk preferences is not driven by religious beliefs per se, but by the social and institutional aspects of church membership. Consistent with this view, a few studies argue that the exogenous and unobserved factors that affect behaviour also contribute to the causal effect of religion on risk attitudes (e.g. Pope et al. 2014; Benjamin et al. 2016). Therefore, examining the social effects of attendance in church activities may also provide a possible explanation for the differing risk attitudes between Catholics and Protestants. Using a representative sample of paid survey participants, Noussair et al. (2013) find that the fraction of Protestants who actively attend church activities is greater than that of Catholics, and Protestants pray more frequently than Catholics. They also document that Protestants hold stronger religious beliefs on average. A few studies tie active church participation to a higher degree of risk aversion, since risk-averse 
individuals are more likely to seek relief and comfort via church attendance (e.g. Hilary and Hui 2009; Shu et al. 2012). Hence, due to the link between risk attitudes and intensity of church involvement, we also expect Catholics to be more risk-tolerant or less risk-averse than Protestants.

\section{Individual characteristics and firm behaviour}

The characteristics of individuals working in an institution are likely to be congruent with the corporate culture. According to social identity theories (e.g. Tajfel 1978; Turner and Reynolds 2010), people derive their personal identity from social group membership, such as ethnicity, gender, nationality, religion and occupation etc. Individuals' behaviour is to a large extent shaped by adopting and internalising the values, norms and attributes of their groups. Therefore, people tend to adjust their behaviour to adapt to the dominant values and principles of groups. This tendency has implications for firm decisions. Personnel psychology literature builds the link between individual and organisational characteristics. Schneider (1987) suggests that a firm does not yield a particular type of employee by chance. It is through a process of attraction to and selection by the firm, as well as natural attrition. The employees' behaviour, in turn, form the firm's culture and determine corporate decisions. Schneider et al. (1995) provide a detailed review of empirical evidence supporting this theory.

Further, employees and managers choose to join a firm that has a culture they feel comfortable with. For example, Vroom (1966) finds that individuals select the workplace that is most helpful in obtaining their valued outcomes. Holland (1976) shows that people desire working environments with compatible personality profiles. Using a sample of 65 CEOs who changed firms from 1991 to 2003, Hilary and Hui (2009) find that when switching employers, CEOs are more likely to join a firm with a similar religious environment as their previous employer. Their results are robust to four specifications, including ones that control for local demographic variables of both previous and current firm headquarter regions, an array of CEO personal characteristics and their motivating reasons for departure. Based on the above two reasons and related empirical evidence, we argue that corporate culture is consistent with the characteristics of employees, including CEOs.

In addition, Kumar et al. (2011) argue that, as one key aspect of local culture, dominant local religion systematically influences the behaviour of local individuals, even though they do not personally follow the prevailing local belief. In other words, individual characteristics are compatible with the local culture. Based on the consistency of individual characteristics and corporate culture developed earlier, we expect individual characteristics, corporate culture and local culture to be congruent. Consistent with this view, Hilary and Hui (2009) also claim that it is natural to expect the corporate culture to align with the institution's local environment. 


\section{Previous evidence on religiosity and risk-taking at the individual and institutional levels}

A bulk of surveys and empirical studies have produced results that support the notion that individual Catholics and institutions headquartered in high-Catholicratio areas generally exhibit more tolerance towards risk-taking or less risk-aversion than individual Protestants and institutions headquartered in high-Protestant-ratio areas. Barsky et al. (1997) utilise the survey data of participants in the Health and Retirement Study (HRS) to elicit their risk-aversion information. The hypothetical question on willingness to gamble on lifetime income indicates that Catholics are less risk-averse than Protestants. Employing the same data source but different methodologies, Halek and Eisenhauer (2001) find consistent results. Through a designed lottery game that involves real stakes, Noussair et al. (2013) find that individual Catholics are less risk-averse than individual Protestants. Other than questionnaires and experiments, Catholics take part more intensively in lotteries than Protestants in real life (Tec 1964). In addition, Catholic individual investors have a stronger preference for stocks with lottery features than Protestant individuals (Kumar 2009). Evidence is found not only at the individual level but also at the business entity level. Institutional investors located in U.S. counties with a higher Catholic-toProtestant ratio are more likely to hold risky investments (Kumar et al. 2011) and have higher investment return volatility, as well as idiosyncratic volatility (Shu et al. 2012). ${ }^{7}$ Moreover, firms headquartered in higher Catholic-to-Protestant ratio regions take long shots to allocate more capital to divisions with greatly skewed expected returns (Schneider and Spalt 2016) and acquire more lottery-type targets with negative net present values in corporate acquisitions (Schneider and Spalt 2017). In addition, companies located in higher Catholic (Protestant) ratio counties are more (less) likely to display aggressive corporate behaviour in terms of excessive compensation package grants to their managers and opportunistic earnings management practice (Grullon et al. 2010).

The empirical evidence in international cross-country studies is less clear. Cultural differences other than religious beliefs may be more pronounced. In their international experimental study L'Haridon and Vieider (2019) fail to find significant differences in risk preferences between Catholics and Protestants. However, for the purpose of our analysis of U.S. life insurance companies, international studies are less relevant.

Given the theory and empirical evidence on the relationship between local religious beliefs and risk in the literature, we formulate the following testable hypothesis for U.S. life insurance companies.

\footnotetext{
7 Kumar et al. (2011) also find that institutional investors located in U.S. counties with a higher Catholic (Protestant) ratio are more (less) likely to hold risky investments. Similarly, Shu et al. (2012) find that mutual funds in higher Catholic (Protestant) ratio counties have higher (lower) investment return volatility and idiosyncratic volatility.
} 
Hypothesis: Insurance companies located in high-Catholic- or low-Protestant-ratio areas take more risks.

\section{Data and methodology}

\section{Sample selection}

In the insurance industry, there are single unaffiliated firms and insurance groups. Insurance groups consist of multiple affiliated subsidiaries, which may be domiciled in various locations across the country. Then, it is difficult to determine which subsidiary's local culture dominantly impacts the group-level decisions. Even if the religious beliefs in the group headquarters may have the primary effects, they might be diluted or dissolved by the conflicting beliefs at the subsidiary level. On the contrary, single unaffiliated insurers operate at a single location. Hence, their headquarters' local culture should have a measurable influence on corporate decisions. In addition, single unaffiliated insurers tend to be smaller than group insurers. Hence, they may have greater latitude in their corporate decisions; risk attitudes of local clientele are more likely to influence their decisions since their customer base may primarily be local (Kumar et al. 2011). In addition, Baker et al. (2011) claim that systematic differences between large group institutions and other institutions exist, which include customer base, geographic office diversification, investment processes and standardised benchmarking practices. Based on these differences, Kumar et al. (2011) argue that religious beliefs would only influence small and moderate-sized institutions without a complex group-subsidiary structure and they empirically support the speculation in their study. In the same vein, we focus our analysis on single unaffiliated insurance companies.

To answer our research question, whether local religious beliefs impact insurance companies' risk-taking, we examine the time period leading up to and covering the recent financial crisis. Focusing on the time period surrounding the recent financial crisis ensures that differences in investment risk-taking become more easily measurable as those differences result in decreased asset valuations and realised or unrealised investment losses. Thus, our initial sample consists of all U.S. single unaffiliated life insurance companies in the Best's Annual Statement File, Life-Health Edition from 2001 to 2010. For some of the risk-taking measures, we need to compute the standard deviations of certain financial statement variables for the past four years. Hence, the year from which all the variables for regression analyses are available is 2004. We apply several sample screening procedures as follows. First, following Berry-Stölzle et al. (2014), we eliminate the insurers that do not primarily write life insurance (life writers) or predominantly write annuities (annuity writers). Life writers are defined as insurers with over two-thirds of net premiums written in 
life lines of business, and annuity writers are defined as those with over two-thirds of net premiums written in annuity lines of business. ${ }^{8}$ As a result, accident and health insurers are removed from the sample. We then drop the firms predominantly operating as reinsurers. Specifically, we exclude observations if the ratio of reinsurance assumed to the sum of direct premiums written and reinsurance assumed (reinsurance business fraction) has a value above 50\%. These screenings leave us with 763 observations or 221 unique insurers. Next, we remove firm-year observations with missing or non-positive total assets, surplus or net premiums written. In addition, we drop insurers with strange reinsurance arrangements. In particular, insurers with a negative reinsurance business fraction are removed. Our final sample comprises 705 firm-year observations or 202 single unaffiliated life insurers for the period 2004-2010. Table OA1 in the Supplementary Material reports the number of observations for each step of the sample selection process.

\section{Religiosity ratios}

The data on local religious beliefs are available from the American Religion Data Archive (ARDA), which is jointly sponsored by the Association of Statisticians of American Religious Bodies and the Glenmary Research Center. ARDA data are based on a series of surveys that are conducted approximately every 10 years. Each survey provides the number of congregations and adherents of Judeo-Christian church bodies in each county. In this study, we utilise the surveys conducted in 2000 and 2010, and the numbers of religious groups included are 149 and 236, respectively. Following the prior literature (e.g. Hilary and Hui 2009; Shu et al. 2012), we calculate the Protestant Ratio (Catholic Ratio) of each county. The Protestant Ratio (Catholic Ratio) is defined as the number of adherents of Protestant denominations (Catholic denominations) within the county divided by the county's total population. Following Kumar et al. (2011), we also define the Catholic-to-Protestant Ratio to capture the relative fractions of Catholics and Protestants in a county. It provides a measure for the sharpest comparison of risk-taking between Catholics and Protestants. Our sample spans from 2004 to 2010, and the religiosity ratios of the survey year 2010 are computed directly. For the non-survey years (2004-2009), we linearly interpolate the religion data in 2000 and 2010 to obtain the values.

To match the county-level religiosity ratios with insurance companies' financial statement data, we first collect the zip code of the corporate administrative office address from Best's Insurance Reports, Life-Health Edition. Then, we obtain the county location for each insurer by matching the zip code with the corresponding

\footnotetext{
${ }^{8}$ We collect net premiums written from the 'Analysis of operations by line of business' page of Best's Annual Statement File, Life-Health Edition as the sum of lines '1 Premiums and annuity considerations for life and accident and health contracts' and ' 2 Considerations for supplementary contracts with life contingencies'. The portion of annuity business is based on the sum of premiums in individual and group annuities. The portion of life business is calculated as the sum of industrial life, ordinary life, group life and credit life.
} 
county using the geographic file from the SAS data library. Finally, we assign the county's religiosity ratios to the insurer located in that county.

\section{Risk-taking measures}

In the insurance literature, Lee et al. (1997) analyse changes in insurance companies' portfolio composition. Assuming investments in stocks are riskier than in bonds, they interpret an increase in stock holdings and decrease in bond holdings in an insurer's portfolio as evidence of increased risk-taking. A number of studies focus on stock insurers and construct market risk-taking measures based on asset pricing models (e.g. CAPM and the Fama-French five-factor model) (e.g. Cummins and Harrington 1988; Barinov et al. 2020) or the dividend discount model (e.g. BerryStölzle and $\mathrm{Xu}$ 2018). For insurance-specific operations, previous proxies for risktaking behaviour include variance of loss ratio (Lamm-Tennant and Starks 1993) and coefficient of variation (CV) of underwriting leverage and CV of solvency ratio for cross-country analyses (Fields et al. 2012). However, most of these previous studies on insurer risk-taking only examine one type of risk. Previous research (e.g. Ho et al. 2013; Che and Xu 2020; Jia et al. 2020) has advocated the use of multiple measures in order to capture the risks taken by insurers thoroughly. Hence, we employ a high-risk indicator and three different measures to gauge different aspects of risk-taking for life insurers.

Berry-Stölzle et al. (2014) provide evidence that insurers that predominately write annuities have substantially more volatile earnings and capitalisation levels than other life and health insurers. Thus, we employ an annuity writer dummy variable to indicate a relatively high level of risk in terms of business model. We expect that insurers in high-Catholic ratio or low-Protestant ratio areas are more likely to be annuity writers, if Catholics are less risk-averse than Protestants.

An insurer's investment portfolio consists of various types of assets, and the riskiness of each category of investment varies. For example, stocks and real estate are relatively high-risk investments compared to fixed income securities, cash and shortterm investments (Lee et al. 1997). Therefore, the relative weight of risky assets in an insurer's investment portfolio affects its insolvency risk. Following the literature (Gaver and Pottier 2005), we compute the ratio of investments in equity securities and real estate to cash and total investments to capture asset risk. ${ }^{9}$

In order to measure the investment risk of an insurer, following Ho et al. (2013), we use the standard deviations of the insurance company's return on investment (ROI). The ROI is defined as the ratio of investment income plus realised capital

\footnotetext{
${ }^{9}$ Under the Statutory Accounting Principles, assets from separate accounts are broken out and presented as a separate line item on the balance sheet. The measure of asset risk does not include separate account assets.
} 
gains to cash and invested assets. ${ }^{10}$ The standard deviations are computed based on a four-year rolling window.

Lastly, we use the standard deviations of the insurance company's return on assets (ROA) to measure the overall risk for shareholders or policyholders. This total risk measure reflects the combination of all the aspects of risks taken by insurers and determines insurers' risk profile (Ho et al. 2013). We define ROA as the ratio of net income to total net admitted assets. ${ }^{11}$ The standard deviations are computed based on a four-year rolling window. Insurer financial statement data are obtained from Best's Annual Statement File, Life-Health Edition.

\section{Model specification}

As discussed in the previous section, annuity writers have more volatile earnings and capitalisation. If Catholics (Protestants) are more (less) tolerant towards risks, we would expect annuity writers to be more (less) likely to be headquartered in high-Catholic (Protestant) ratio regions. To test this prediction, we estimate a multiperiod logit regression of an annuity writer indicator on local religiosity ratios and various county-level and state-level demographic characteristics:

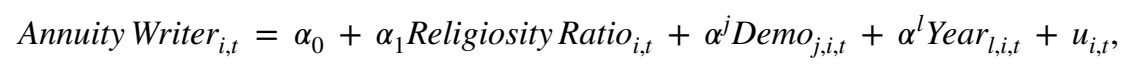

where Annuity Writer is a dummy variable that takes the value of one if insurer $i$ has more than two-thirds of the total net premiums written in annuity lines of business in year $t$, and zero otherwise. ReligiosityRatio includes the three religiosity variables, namely Catholic-to-Protestant Ratio, Catholic Ratio and Protestant Ratio, where we use only one at a time in each regression. ${ }^{12}$ Demo is a vector consisting of demographic variables-Age, Education, Income, Population, Minority, Married,

\footnotetext{
${ }^{10}$ The 'net investment income' and 'net realised capital gains' in the summary of operations only reflect the investment performance of general account assets and exclude separate account assets whose investment gains directly benefit policyholders. Therefore, our measure of investment risk does not include separate account assets.

${ }^{11}$ While life insurance companies do not profit from the investment gains associated with separate accounts, they make money by providing life insurance coverage and annuities associated with the policies tied to separate accounts and by charging fees to cover expenses. The revenue and expenses associated with these policies are included in an insurance company's net income. Therefore, our overall measure of firm risk, the standard deviations of an insurance company's ROA, captures fluctuations in overall profitability, including fluctuations in the profitability of separate account products.

${ }^{12}$ When using Catholic-to-Protestant Ratio as the religiosity variable, the model does not control for the total religiousness of insurers' headquarter counties. For example, County A with a Catholic Ratio and a Protestant Ratio of 5\% each and County B with $40 \%$ each have the same Catholic-to-Protestant Ratio of 1. But, the total religiousness of County A (assuming only Catholics and Protestants for simplicity) is $10 \%$, whereas that of County B is $80 \%$. In order to address this concern, we check the variation of total religiosity ratios (total number of religious adherents divided by the total population of a county) across counties, and find that it is relatively small (with a 25th percentile, median and 75th percentile 0.492 , 0.564 and 0.635 , respectively). Further, when examining Catholic-to-Protestant Ratio, the models are robust to adding the total religiosity ratio as an additional control variable when regressing on the annuity writer indicator and all risk-taking measures.
} 
MaletoFemale, Population Density and the Dependency Ratio. Year fixed effects are included, and $u$ is the error term. We control for county-level demographic variables to ensure that the impacts attributed to religion truly reveal the effects of the predominant local religion, as opposed to other socio-economic aspects that may be correlated with religious beliefs. We include the state-level dependency ratio to control for differences in the demand for annuities across states. Standard errors are corrected for two-way clustering by firm and by year. ${ }^{13}$

Next, we investigate the effects of local religious beliefs on insurers' risk-taking behaviour, controlling for both firm-level and county-level characteristics. The model specification is as follows:

$$
\text { Risk-taking }_{i, t}=\alpha_{0}+\alpha_{1} \text { Religiosity Ratio }_{i, t}+\alpha^{j} \text { Insurer }_{j, i, t}+\alpha^{k} \text { Demo }_{k, i, t}+\alpha^{l} \text { Year }_{l, i, t}+u_{i, t},
$$

where Risk-taking represents the three risk measures defined earlier: asset risk, investment risk and total risk for insurer $i$ in year $t$. ReligiosityRatio stands for the three religiosity measures, namely Catholic-to-Protestant Ratio, Catholic Ratio and Protestant Ratio. We expect the Catholic-to-Protestant Ratio and Catholic Ratio to be positively associated and Protestant Ratio to be negatively related to the risktaking measures. Insurer is a vector of firm-level control variables, including an indicator equal to 1 if the firm is licenced in the state of New York and the number of states the insurer is licenced in to control for differences in the stringency of state regulation, ${ }^{14}$ firm size, capital-to-assets ratio, net premium growth, reinsurance use, geographic Herfindahl-Hirschman Index (HHI), as well as indicator variables of mutual insurer, stock insurer, annuity writer, life writer and publicly-traded insurer. Demo is a vector of county-level demographic characteristics including Population Age, Education, Income, Population, Minority, Married, MaletoFemale and Population Density, as well as the state-level Dependency Ratio. The model also includes year fixed effects to control for potential heterogeneity in risk-taking behaviour over time. Finally, $u$ is the error term. We use a tobit model with upper and lower bounds and one-way robust standard errors corrected for firm-level clustering to study asset risk-taking. ${ }^{15}$ Regressions on investment risk and total risk are estimated using

\footnotetext{
${ }^{13}$ The results are robust to using two-way standard errors corrected for county clustering and year clustering.

${ }^{14}$ The state of New York is known for having the most stringent regulation of life insurance companies and New York insurance regulation applies on an extraterritorial basis (Pottier and Sommer 1998; Pottier 2007). Thus, an insurer licenced in New York must adhere to New York regulations wherever the insurer operates. We include an indicator in the model to capture differences in regulation between New York and other states. In addition, we include a variable that captures the number of states an insurer is licenced in. If an insurer is licenced in more states then the insurer has to adhere to the regulations of more states and it is more likely that the set of regulations the insurer has to adhere to includes more stringent regulations.

${ }^{15}$ Since the asset risk is calculated as ratios and is bounded between 0 and 1 , it is more appropriate to use tobit regressions to model asset risk as a dependent variable. In the pooled OLS models for investment risk and total risk, we report two-way robust standard errors corrected for clustering by firm and by year. To be consistent, we would prefer a tobit model with upper and lower bounds and two-way robust standard errors as well. However, such a tobit model does not seem to exist yet. Therefore, we use a tobit model with upper and lower bounds and one-way robust standard errors corrected for firm-level clustering to study insurer asset risk-taking behaviour.
} 
pooled ordinary least squares (OLS) with standard errors corrected for two-way clustering by firm and by year. ${ }^{16}$ We perform regressions separately on asset risk, investment risk, and total risk for all sample insurers, insurers that primarily write annuities, and those that primarily write life business, respectively.

The firm-specific control variables included in the model are coded as follows. Firm size is measured by the natural logarithm of total net admitted assets. The capital-to-assets ratio is calculated as the fraction of total capital and surplus to total net admitted assets. Net premium growth is measured as the change of net premiums written from the previous year divided by the previous year's net premiums written. Reinsurance use is constructed as the percentage of reinsurance ceded to the sum of direct premiums written and reinsurance assumed. Since a reinsurance use ratio outside the range of 0 and 1 is unreasonable, we winsorise the ratio at 0 and 1. Geographic HHI is measured as $\Sigma\left(D B_{i} / T D B\right)^{2}$, where $D B_{i}$ is the value of total direct premiums and annuity considerations in state $i$, and $T D B$ is the insurer's total direct premiums and annuity considerations across the U.S. In order to control for heterogeneities in risk-taking that might arise from differences across organisational forms, we include the mutual and stock insurer dummy variables and the omitted category is other organisational forms. The annuity writer or life writer indicator is also added to address the distinct risk-taking behaviour due to the different business models for insurers that primarily write annuity business and those that primarily write life business. In addition, we include an indicator of whether an insurer is publicly-traded to control for the differences in risk-taking between public and private insurers.

We obtain the county-level demographic data from the U.S. Census Bureau, which include the median age of the county population (Population Age), the fraction of highly educated people (bachelor's degree or higher) in the population that are 25 years or older (Education), the per capita personal income (Income), the county's total population (Population), the fraction of the minority population that is not non-Hispanic White alone (Minority), the ratio of married households to the total number of households (Married), the ratio of the male population to the female population (MaletoFemale) and the total population of a county divided by the county's area (Population Density).

\section{Results}

\section{Descriptive statistics}

Table 1 displays the summary statistics for the variables used in this study. All monetary values are inflation adjusted and converted to constant 2000 U.S. dollars. The results indicate that a typical single unaffiliated insurance company in our sample is

\footnotetext{
16 Shu et al. (2012) report the standard errors that are corrected for two-way clustering by county and by year. As a robustness check, we also correct standard errors for the two-way clustering by county and by year, and the results are very similar.
} 
Table 1 Summary statistics

Percentile

N Mean St. Dev 5th 25th Median 75th 95th

Religiosity ratios

Catholic-to-Protestant Ratio 705

Catholic Ratio

Protestant Ratio

705

1.393

1.498

0.049

0.326

0.893

2.018

4.655

isk-taking measures

Asset Risk

Investment Risk

0.223

0.141

0.030

0.093

0.194

0.342

0.464

Total Risk

705

0.281

0.085

0.161

0.220

0.398

0.589

Firm characteristics

Firm Size

Capital-to-Assets Ratio

Net Premium Growth

Reinsurance Use

Geographic HHI

Mutual

Stock

Annuity Writer

Life Writer

Publicly Traded

Annuity Bus. Fraction

Ordinary Annuity Bus.

Fraction

Group Annuity Bus. Frac- 705 tion

Life Bus. Fraction

A\&H Bus. Fraction

Other Bus. Fraction

Industrial Life Bus. Fraction

Ordinary Life Bus. Fraction

Supplemental Bus. Fraction

Credit Life Bus. Fraction

Group Life Bus. Fraction

Group A\&H Bus. Fraction

A\&H Credit Bus. Fraction

A\&H Other Bus. Fraction

Other Fraction

Group Bus. Fraction

Firm Age

Number of Licences

NYS Licenced

ocal demographic variables

70

705

527

527

0.072

0.007

0.110

0.000

0.007

0.029

0.076

0.335

$0.013 \quad 0.041$

001

0.003

.005

0.009

0.022

0.00

0.006

0.012

0.039

705

18.445

2.379

487

18.679

20.195

22.393

610

0.245

0.250

0.042

0.077

0.137

0.303

0.888

705

0.265

4.239

$-0.348-$

0.164

0.240

0.000

$-0.113-0.018$

0.073

0.649

704

0.463

0.376

0.048

0.106

0.047

0.242

0.747

705

0.112

0.316

0.000

0.000

0.312

0.954

1.000

705

0.705

0.456

0.000

0.000

0.000

0.000

1.000

705

0.261

0.439

0.000

0.000

1.000

1.000

1.000

705

0.739

0.439

0.000

0.000

0.000

1.000

1.000

705

705

0.050

0.217

0.000

0.000

1.000

1.000

1.000

0.278

0.403

0.000

0.000

0.000

0.000

705

0.257

0.384

0.000

0.000

0.068
0.057

0.690

0.984

0.020

0.102

0.00

0.000

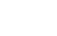

0.314

0.973

705

705

0.684

0.396

0.011

0.304

0.000

0.000

0.042

705

0.034

0.004

0.092

0.000

0.000

0.832

$0.980 \quad 1.000$

0.011

0.036

0.000

0.000

0.000

0.025

0.235

705

705

0.537

0.070

0.000

0.000

0.000

0.001

0.017

705

0.004

0.000

0.112

0.000

0.000

0.029

705

705

0.062

0.036

0.000

0.000

0.697

0.907

1.000

0.075

0.223

0.000

0.00

0.016

705

0.013

0.243

0.000

000

0.000

0.000

705

705

0.009

0.052

0.000

0.000

0.000

0.025

0.767

0.000

0.000

0.127

0.011

0.000

0.000

0.000

0.074

705

0.000

0.004

0.000

0.000

0.000

0.003

0.063

705

705

0.109

0.262

0.000

0.000

0.000

$0.000 \quad 0.000$

$67.586 \quad 33.652$

21.000

4

5.000

0.000

$0.054 \quad 0.889$

705

$22.054 \quad 19.297$

1.000

4.000

$55.000 \quad 101.000 \quad 124.000$ 
Table 1 (continued)

\begin{tabular}{lrrrrrrrrr}
\hline & \multicolumn{10}{c}{ Percentile } \\
\cline { 6 - 10 } & N & Mean & St. Dev & 5th & 25th & Median & 75 th & 95 th \\
\hline Population Age & 705 & 36.345 & 3.134 & 31.410 & 34.120 & 36.380 & 38.400 & 41.300 \\
Education & 705 & 31.103 & 9.573 & 16.640 & 25.320 & 29.900 & 35.300 & 47.800 \\
Income & 705 & 22.855 & 5.770 & 16.942 & 19.378 & 21.300 & 24.824 & 32.376 \\
Population & 705 & 0.922 & 1.192 & 0.044 & 0.214 & 0.603 & 1.107 & 3.519 \\
Minority & 705 & 10.498 & 15.803 & 0.200 & 2.740 & 6.150 & 12.350 & 29.590 \\
Married & 705 & 24.449 & 19.132 & 2.200 & 12.160 & 21.280 & 30.420 & 54.880 \\
MaletoFemale & 705 & 95.031 & 3.546 & 89.900 & 92.500 & 94.420 & 97.000 & 101.400 \\
Population Density & 705 & 2.803 & 9.442 & 0.071 & 0.320 & 0.981 & 1.996 & 5.609 \\
Dependency Ratio & 705 & 59.811 & 2.681 & 55.437 & 58.479 & 60.000 & 61.186 & 64.312 \\
\hline
\end{tabular}

This table presents the summary statistics of the variables. The variable definitions are reported in the Appendix. All monetary values are inflation adjusted and converted to constant 2000 U.S. dollars

located in a county with $19.4 \%$ Catholic population and $22 \%$ Protestant population, which makes the county Catholic-to-Protestant ratio 0.893. However, the Catholicto-Protestant ratio of a typical county across the U.S. is 0.253 , with $8.31 \%$ Catholics and $35.05 \%$ Protestants. This is because our sample insurers (and insurance companies in general) are clustered in regions with relatively dense Catholic populations; the cities with the most sample insurers include Chicago, Cincinnati, New York City and Dallas. Nevertheless, there are also substantial variations in local religious beliefs in our sample. As demonstrated in Table 1, the 75th percentile of Catholicto-Protestant Ratio (2.018) is more than six times that of the 25th percentile (0.326); we observe a similar pattern with the Catholic Ratio and Protestant Ratio. In addition, our insurer sample exhibits significant geographic dispersion. The number of sample insurers varies from year to year, and the average number for the seven-year sample period is $100.714 .{ }^{17}$ Untabulated results reveal that these insurers are spread out in 42 states, or 75 counties, and the states with the highest insurer concentrations are Texas $(9.36 \%$ of sample), Pennsylvania ( $8.79 \%$ of sample), Illinois $(8.09 \%$ of sample), Ohio (6.67\% of sample), New York (6.24\% of sample) and Louisiana (5.11\% of sample).

As the proxy for asset risk, the stock and real estate investment fraction for an average sample insurer is $7.2 \%$. In order to gauge the Investment Risk and Total Risk, we need to calculate the standard deviations of certain accounting measures for the past four years. Thus, the number of observations for these two risk measures is lower than for the other variables. A typical sample insurer has a volatility of ROI of 0.005 and a volatility of ROA of 0.006 . There are wide variations in these two risk measures. For example, the 75 th percentile for ROA volatility is 0.012 , three times

\footnotetext{
17 More specifically, there are 107 single unaffiliated insurers in our sample in 2004, 104 in 2005, 102 in 2006, 97 in 2007, 87 in 2008, 88 in 2009 and 120 in 2010.
} 
larger than that of the 25 th percentile (0.003). A similar pattern is also observed for ROI volatility.

The average total assets across the sample insurers are USD 102.462 million $\left(\mathrm{e}^{18.445}\right)$, which indicates that our sample is comprised of small and moderate-sized firms. They are expected to be more susceptible to local religions than large firms (Kumar et al. 2011). A typical sample insurer has a capital-to-asset ratio of $13.67 \%$, net premium growth of $-1.84 \%$, reinsurance use of $4.72 \%$ and geographic HHI of 0.312 . Our sample consists of $11.20 \%$ mutual insurers and $70.49 \%$ stock insurers. In the sample, $26.10 \%$ are predominately life insurance writers and $73.90 \%$ are annuity writers. In addition, $4.97 \%$ of the sample are publicly-traded firms, with the majority of the sample made up of private firms. On average, life insurance makes up $68.44 \%$ of the business of the sample insurance companies, annuities account for $27.77 \%$ (with a breakdown between the two major components of $25.74 \%$ for ordinary individual annuity and $2.03 \%$ for group annuity), accident \& health makes up $3.37 \%$ and other business has a share of $0.43 \%$. The insurers in our sample have fairly long histories, with an average age of 67.586 years.

We form quintile portfolios of the insurers sorted by Catholic-to-Protestant Ratio, Catholic Ratio and Protestant Ratio, respectively, and then calculate the means of the firm characteristics for each quintile. We report the univariate differences between the highest and lowest quintiles and the corresponding significance in Table OA2 in the Supplementary Material.

\section{Regression analyses of risk-taking}

Insurers that predominantly write annuities have more volatile earnings and capitalisation than other types of life and health insurance writers (Berry-Stölzle et al. 2014). In other words, they are riskier. Based on the risk attitudes of Catholics and Protestants, we expect that annuity writers are more likely to be located in areas with a large Catholic (small Protestant) population. To investigate whether annuity writers are more common in Catholic- or Protestant-denominated counties, we estimate a multi-period logit regression of annuity writer dummy with year fixed-effects on various county-level demographic characteristics, including local religious beliefs. The standard errors are corrected for two-way clustering by firm and by year. As reported in Table 2, the results show that annuity writers are more commonly found in counties with a higher concentration of Catholics or lower concentration of Protestants. We also find that annuity writers are more likely to be located in counties with older populations and lower per capita income. Employees of insurance companies living in counties with an older population and lower per capita income might appreciate the financial security associated with annuity products more than employees living in a younger and more affluent environment, resulting in a local culture that is more supportive of annuity products. Furthermore, population density is positively related to the headquarter county of annuity writers. The higher the population density, the more urbanised an area is. Hence, the population density can be regarded as a proxy for urbanisation. The result shows that annuity writers are 
Table 2 Multi-period logit regression of annuity writer indicator

\begin{tabular}{|c|c|c|c|}
\hline \multicolumn{4}{|c|}{ Indicator: Annuity writers } \\
\hline Catholic-to-Protestant Ratio & $\begin{array}{c}0.085 \\
(0.118)\end{array}$ & & \\
\hline Catholic Ratio & & $\begin{array}{c}2.356^{*} \\
(1.353)\end{array}$ & \\
\hline Protestant Ratio & & & $\begin{array}{c}-3.532^{* * *} \\
(1.454)\end{array}$ \\
\hline Population Age & $\begin{array}{l}0.203 * * \\
(0.080)\end{array}$ & $\begin{array}{l}0.176^{* *} \\
(0.080)\end{array}$ & $\begin{array}{l}0.198 * * \\
(0.077)\end{array}$ \\
\hline Education & $\begin{array}{c}0.068 \\
(0.049)\end{array}$ & $\begin{array}{c}0.062 \\
(0.049)\end{array}$ & $\begin{array}{c}0.056 \\
(0.048)\end{array}$ \\
\hline Income & $\begin{array}{r}-0.146 \\
(0.091)\end{array}$ & $\begin{array}{r}-0.147 \\
(0.089)\end{array}$ & $\begin{array}{r}-0.151^{*} \\
(0.089)\end{array}$ \\
\hline Population & $\begin{array}{c}0.266^{*} \\
(0.157)\end{array}$ & $\begin{array}{c}0.210 \\
(0.158)\end{array}$ & $\begin{array}{c}0.154 \\
(0.159)\end{array}$ \\
\hline MaletoFemale & $\begin{array}{c}0.028 \\
(0.067)\end{array}$ & $\begin{array}{c}0.037 \\
(0.064)\end{array}$ & $\begin{array}{c}0.028 \\
(0.062)\end{array}$ \\
\hline Minority & $\begin{array}{r}-0.026 \\
(0.019)\end{array}$ & $\begin{array}{r}-0.020 \\
(0.021)\end{array}$ & $\begin{array}{r}-0.017 \\
(0.020)\end{array}$ \\
\hline Married & $\begin{array}{r}-0.005 \\
(0.019)\end{array}$ & $\begin{array}{r}-0.008 \\
(0.020)\end{array}$ & $\begin{array}{r}-0.008 \\
(0.020)\end{array}$ \\
\hline Population Density & $\begin{array}{l}0.056^{* *} \\
(0.025)\end{array}$ & $\begin{array}{l}0.059 * * \\
(0.026)\end{array}$ & $\begin{array}{l}0.054 * * \\
(0.026)\end{array}$ \\
\hline Dependency Ratio & $\begin{array}{c}0.061 \\
(0.072)\end{array}$ & $\begin{array}{c}0.071 \\
(0.075)\end{array}$ & $\begin{array}{c}0.056 \\
(0.068)\end{array}$ \\
\hline Constant & $\begin{array}{c}-13.868 * \\
(8.027)\end{array}$ & $\begin{array}{c}-14.472 * \\
(7.634)\end{array}$ & $\begin{array}{r}-11.642 \\
(7.579)\end{array}$ \\
\hline Year dummies & Yes & Yes & Yes \\
\hline Observations & 705 & 705 & 705 \\
\hline Pseudo R-sq & 0.084 & 0.093 & 0.111 \\
\hline
\end{tabular}

This table presents the results from a multi-period logit regression on annuity writer indicator with year fixed-effects. The variable definitions are reported in the Appendix. We calculate the $t$-statistics using two-way clustered standard errors (in parentheses) by firm and by year. $* * *, * *$ and $*$ denote statistical significance at the $1 \%, 5 \%$ and $10 \%$ levels, respectively

more common in urban areas. This may be due to the fact that there is a larger pool of skilled workers in urban areas compared to more rural locations.

We acknowledge that there may be differences in the demand for annuities across different geographic regions. However, most life insurance companies sell their products in multiple states with a wide variety of demand characteristics. We therefore do not expect differences in the demand for annuities to have a major, systematic 
impact on our results. The median insurer in our annuity writer indicator regression sample only generates $43.7 \%$ of premiums written in its home state. ${ }^{18,19}$

We further perform regressions of multiple risk-taking measures from various aspects that control for a broad set of insurer characteristics and county-level demographic variables. In order to improve readability of the coefficients of the explanatory variables, the dependent variables are multiplied by 100 in all multivariate models.

Table 3 reports the regression results on asset risk-taking. The models in the first three columns are performed for the full sample of insurers. Even though the signs are as expected for the three religiosity ratios, the coefficients are not significant. Due to the systematic differences in risk-taking behaviour between insurers that primarily write annuities and those that primarily write life business, we separate the analysis for these two major types of insurers with diverse business concentrations. The middle three columns report the findings for annuity writers. Consistent with our hypothesis, the results show that the Catholic-to-Protestant Ratio and Catholic Ratio of annuity providers' headquarter counties are positively associated with their asset risk, as measured by the ratio of investments in equity securities and real estate to cash and total investments. The Protestant Ratio of annuity writers' headquarter counties is negatively associated with their asset risk. Additionally, smaller annuity insurers, and those with less net premium growth, reinsurance use and geographic concentration take more asset risk. Mutual insurers take more asset risk than the omitted category of insurers (insurers with organisational forms other than stock

\footnotetext{
18 The median insurer in our asset risk regression sample (which includes the largest number of observations among all regression samples of risk-taking measures) generates as low as $31.2 \%$ of premiums written in its home state (see Table OA3 in the Supplementary Material).

${ }^{19}$ We perform a robustness check controlling for all possible time-invariant, state-level effects, including possible demand-side effects. Table OA4 in the Supplementary Material presents the results. We lose statistical power by adding 51 additional indicator variables (for the 50 states and Washington, D.C.) to a logit model with a binary dependent variable because observations that can be perfectly predicted by one of the indicator variables have to be removed from the sample before estimating the model, reducing the sample to 544 observations. To further control for differences across insurers' home states, we add state-level versions of the following variables to the model and re-estimate the model: Population Age, Education, Income, Population, MaletoFemale, Minority, Married and Population Density. Table OA5 in the Supplementary Material reports the results. The variable descriptions can be found in Panel A of Table OA6 in the Supplementary Material and summary statistics are presented in Panel B. Alternatively, we include indicator variables for different geographic regions of the U.S. to the baseline model. Table OA22 in the Supplementary Material reports the results; the variable descriptions can be found in Table OA23 in the Supplementary Material. The results of these models are weaker than the results in Table 2, but continue to support our hypothesis.
} 


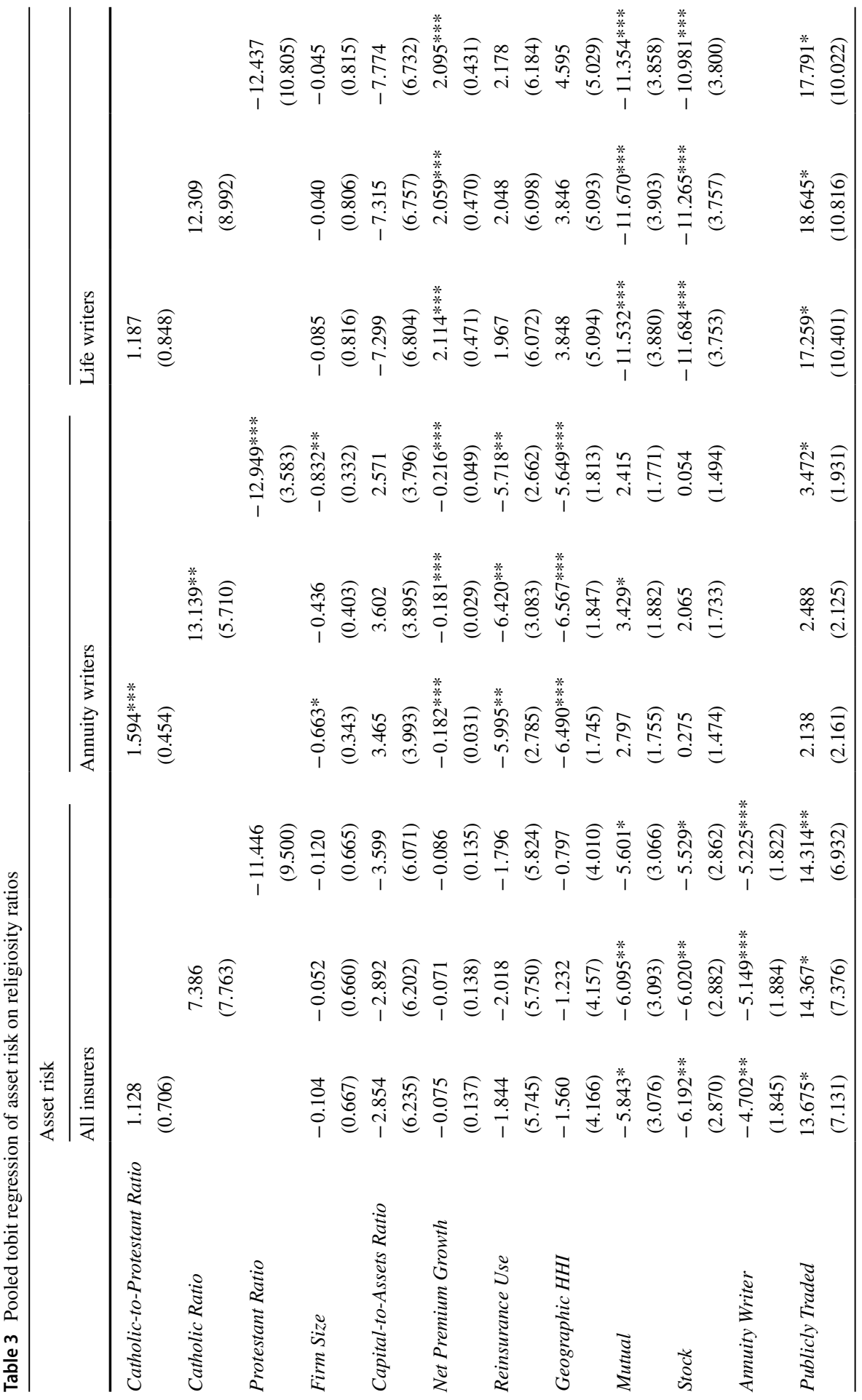




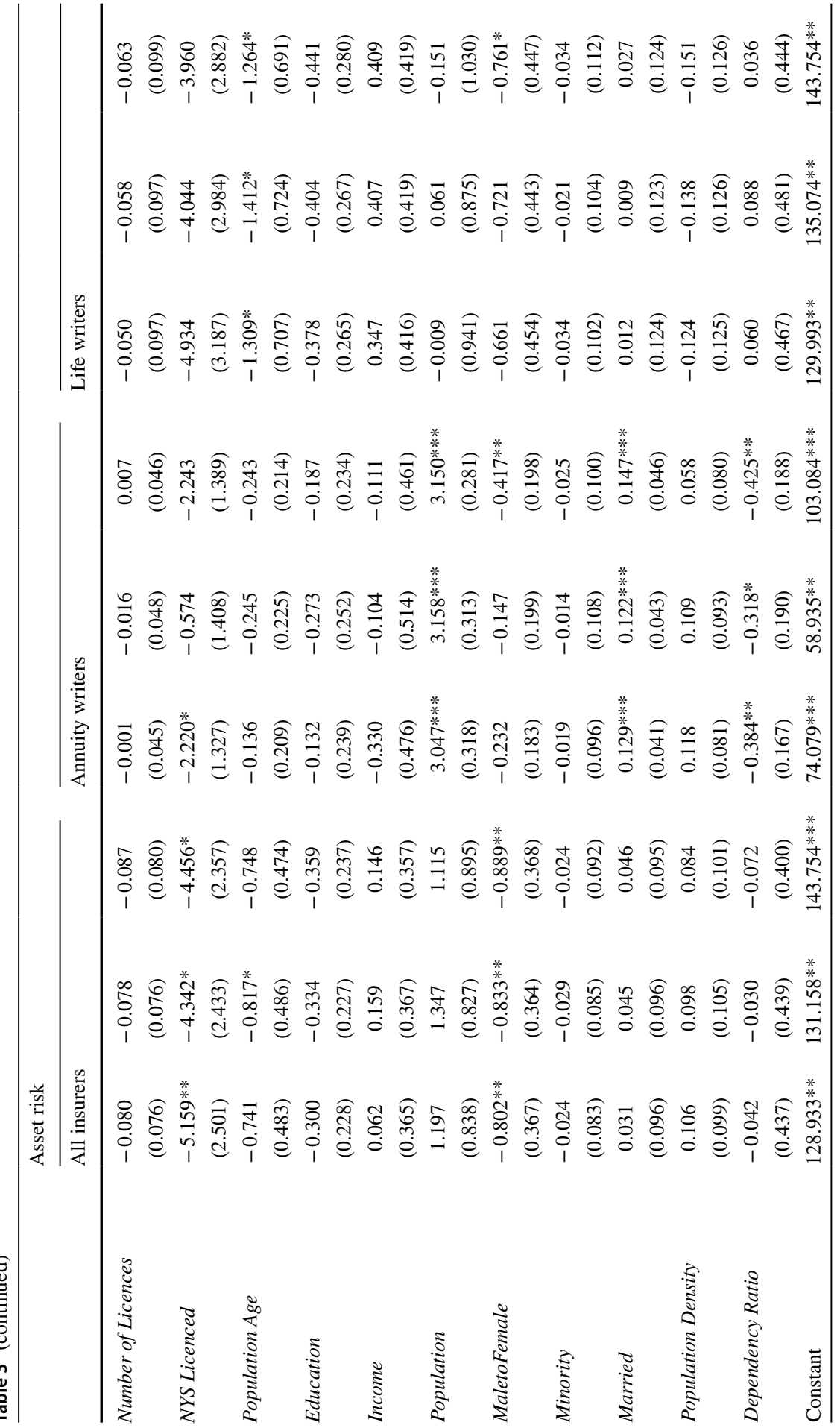

站。 


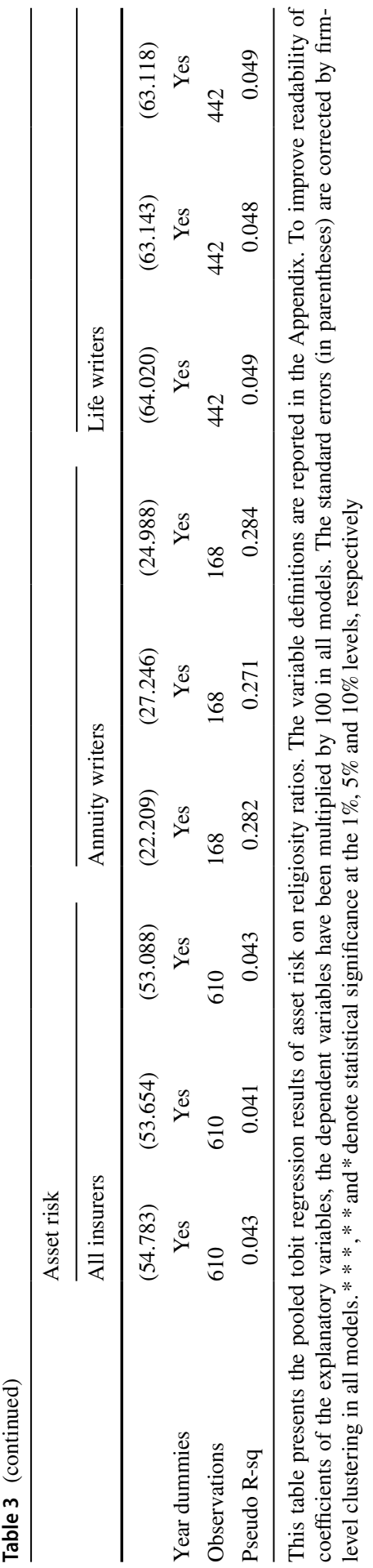


or mutual). ${ }^{20}$ We do not find evidence that religion affects asset risk-taking for life writers.

The results of insurers' investment risk-taking behaviour are exhibited in Table 4. We again separate our regression analysis for the full sample of firms, annuity providers and life providers. We do not find significant effects of local religion on all insurers in general. However, given the systematic differences between annuity writers and life writers, the impact of religion on these two types of insurer may offset each other. When focusing on annuity providers, we find those located in high Catholic-to-Protestant Ratio or low Protestant Ratio counties take more investment risk, captured by the standard deviation of a firm's ratio of investment income plus realised capital gains to the total invested net admitted assets (ROI) for the past four years. In general, annuity writers with a higher capital-to-assets ratio take more investment risk. Stock insurers take more investment risk than mutual insurers and insurers with other organisational forms. We do not find evidence that religion affects investment risk-taking for life writers.

Table 5 reports the results of total risk-taking on religiosity ratios as well as firm and county characteristics. When focusing on insurers that predominantly write annuities, we find that those located in high Catholic-to-Protestant Ratio, high Catholic Ratio or low Protestant Ratio counties take more total risk, measured by the standard deviations of firms' ratio of net income to the total net admitted assets (ROA) for the past four years. This risk measure encompasses various aspects of risk sources and represents the most important overall risk for shareholders or policyholders (Ho et al. 2013). The findings indicate that stock annuity insurers take significantly more total risk than mutual and other types of insurers, which is consistent with the prior literature (Mayers and Smith 1986). In addition, across all nine columns of regressions, we find consistent and significant results that single unaffiliated insurers (including both annuity writers and life writers) with higher capitalto-assets ratio and net premium growth take more total risk. A higher capital-toassets ratio may provide an insurer a larger cushion to absorb potential losses caused by total risk-taking; higher net premium growth is usually associated with greater growth opportunities, which may lead to higher uncertainty in a firm's ROA. Lastly, the adjusted R-squared on three measures of religiosity ratios for annuity providers range from 0.819 to 0.837 . This demonstrates that the models explain the majority of the variations in insurers' total risk-taking activities. We do not observe the influence of religion on the full sample of insurers and life provider subsample. Life

\footnotetext{
20 The coefficients of the Net Premium Growth variable have different signs for the subsamples of annuity writers and life writers in Table 3 . The coefficient for life writers is positive and significant, indicating that fast growing life writers tend to invest more in stocks and real estate than slower growing companies. Since life insurance contracts are usually contracts where the expected payout for new clients is years in the future, life insurers invest a larger fraction of the premium in stocks. The coefficient of the Net Premium Growth variable for annuity writers, on the other hand, is negative and significant, indicating that fast growing annuity writers tend to invest less in stocks and real estate than slower growing companies. A substantial part of new annuity purchases are annuities with immediate benefits. For such products, annuity writers need to choose a more liquid asset allocation with low volatility and stocks and real estate will receive less weight.
} 


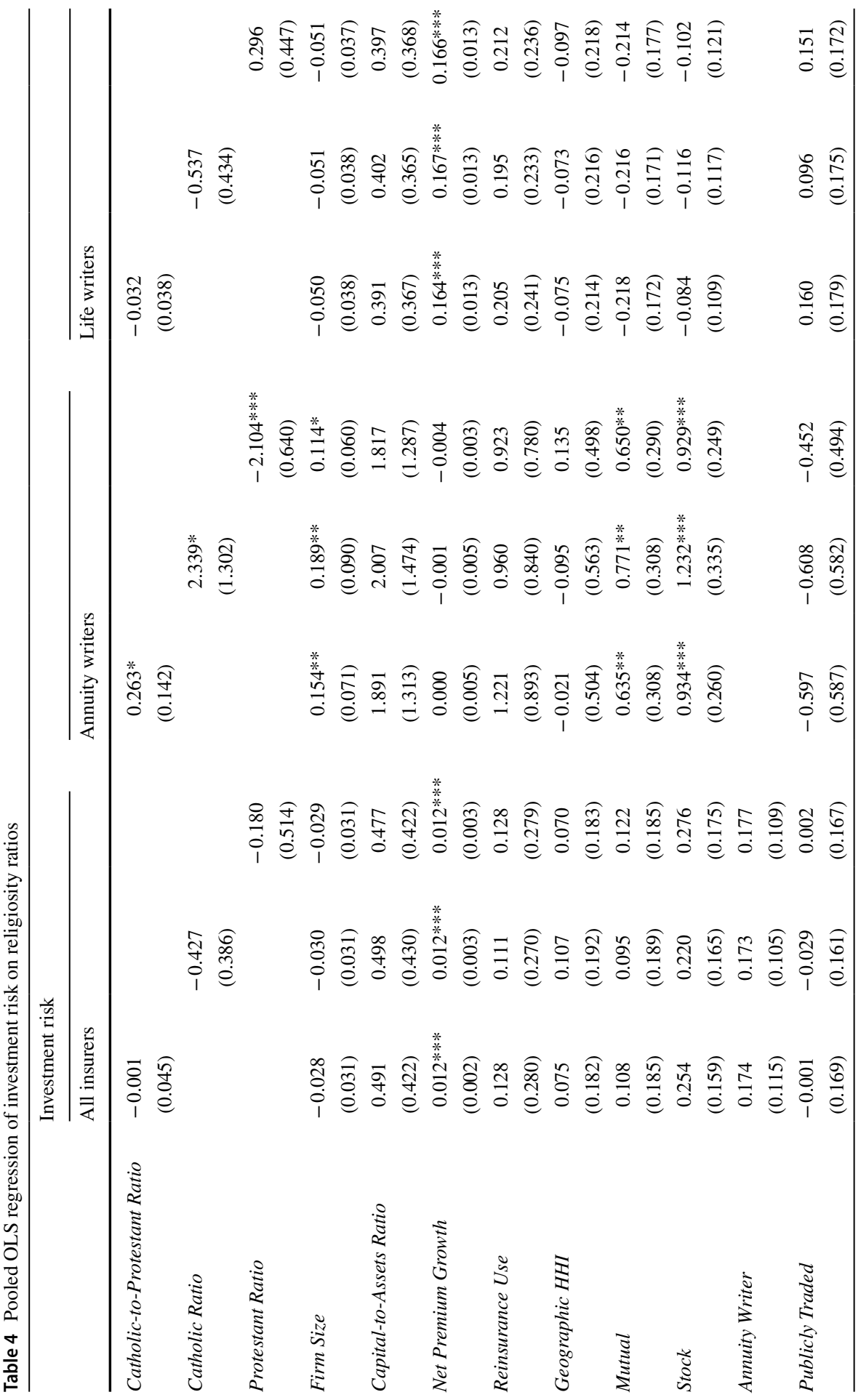

聇。 


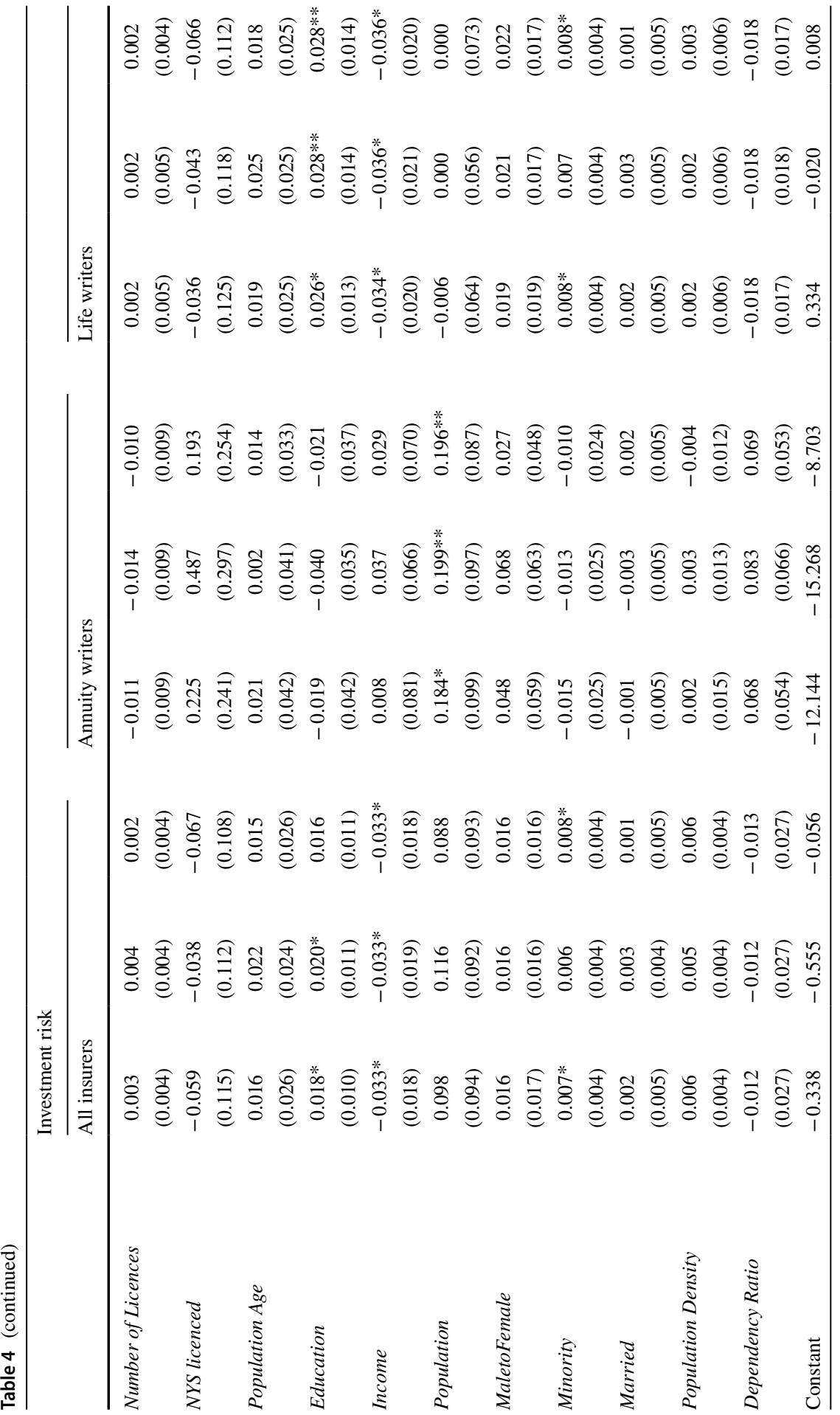

站。 


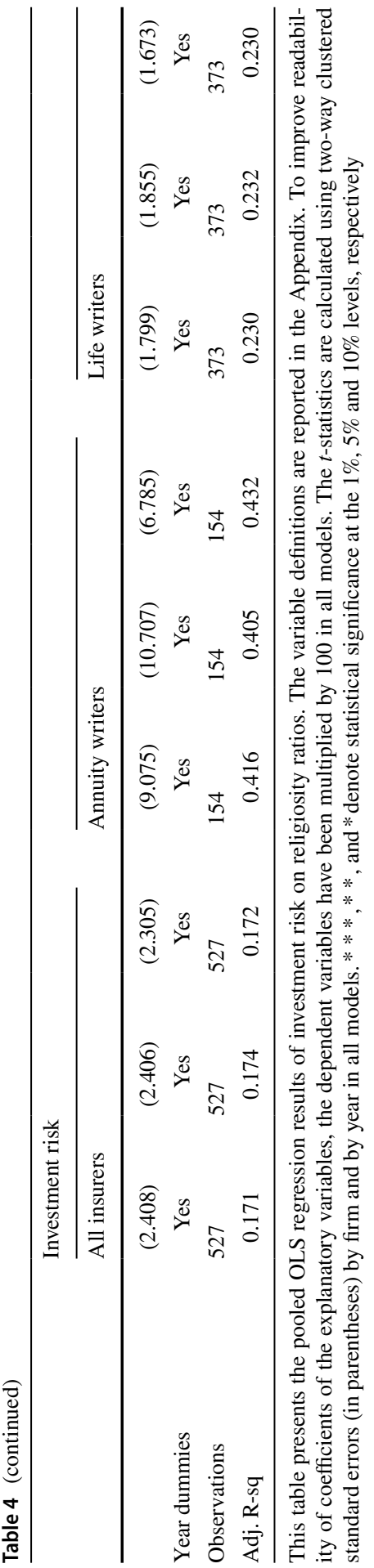




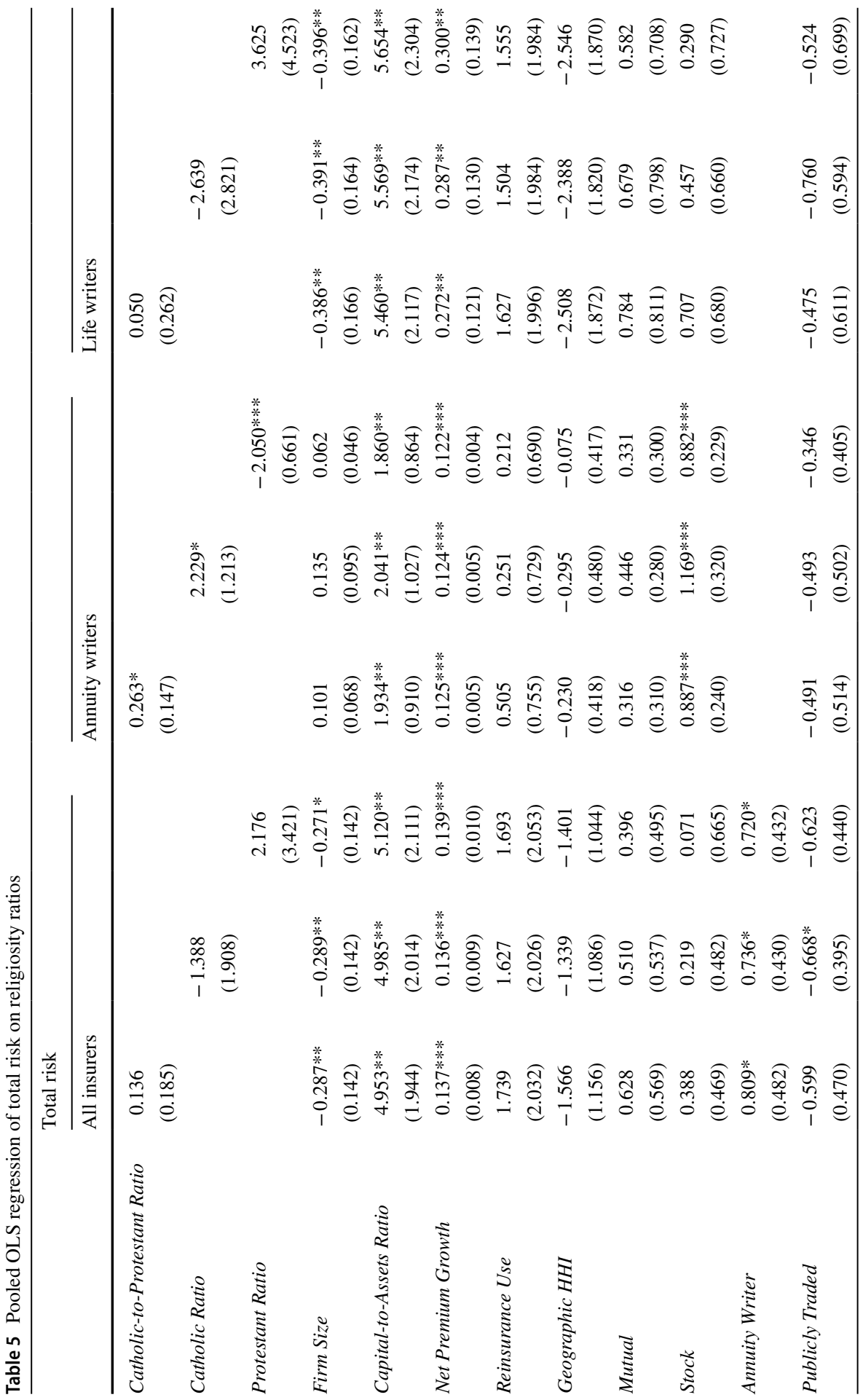

站。 


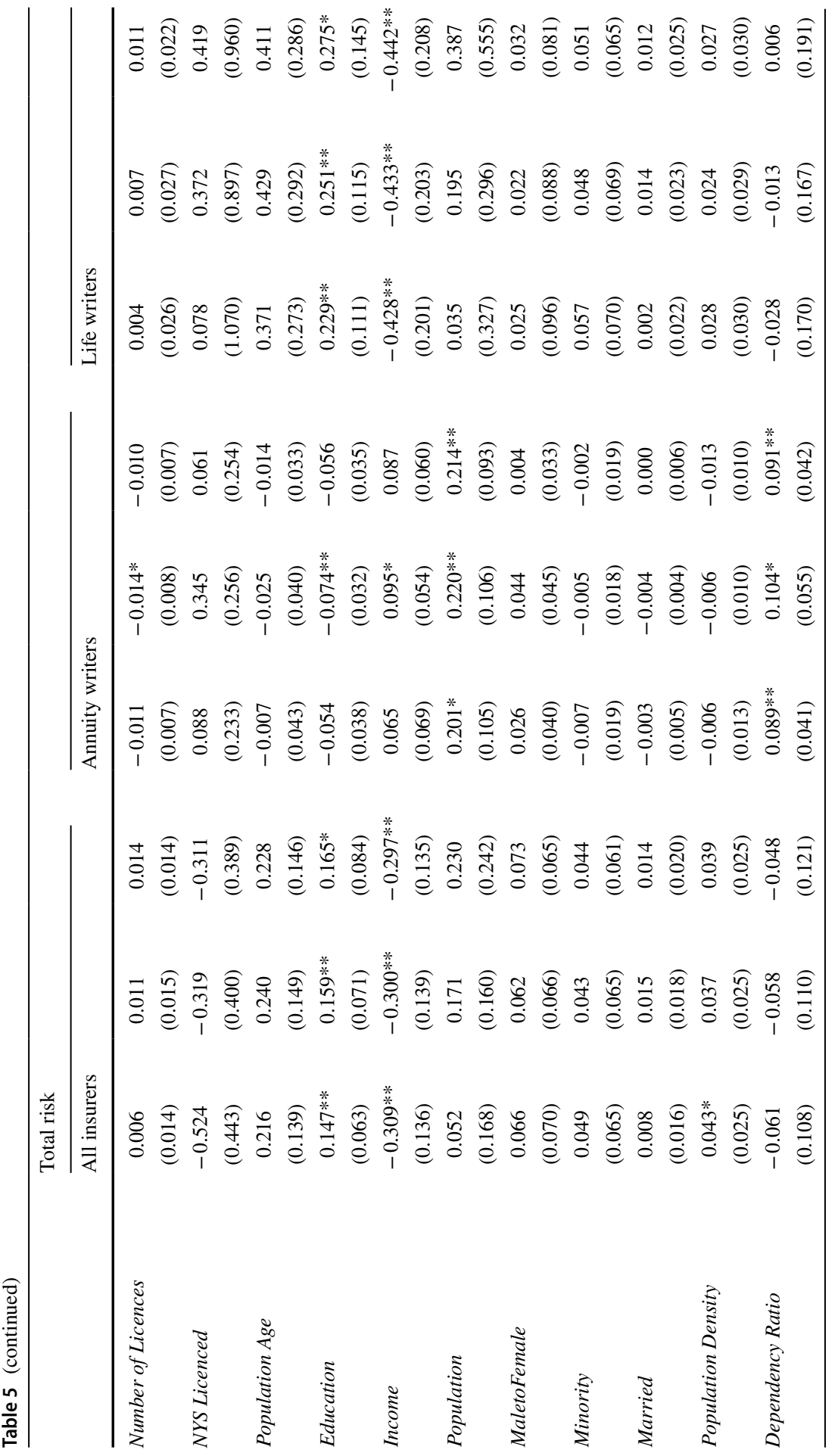




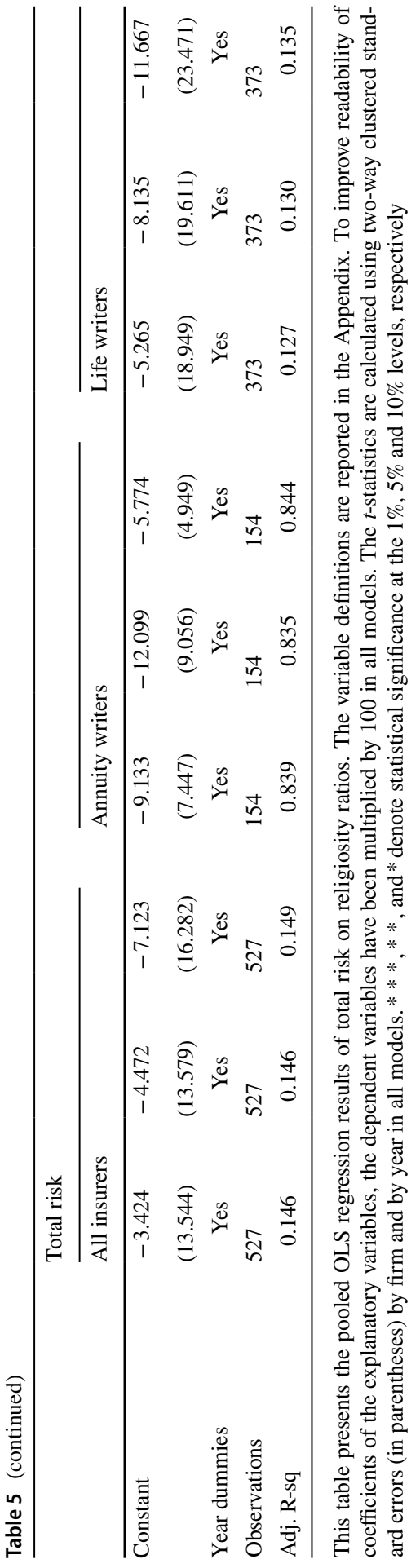

舟 
insurance companies that primarily offer annuities are riskier, on average, than life insurance companies that primarily offer life insurance contracts (Berry-Stölzle et al. 2014). The statistical relationship between local religious beliefs and insurance companies' risk-taking might be more pronounced and therefore easier to detect for annuity writers with a relatively high average level of risk and harder to detect for life writers with a relatively low level of risk.

In addition to Catholic Ratio and Protestant Ratio, we collect the number of adherents for the two groups, Mainline Protestant and Evangelical Protestants, separately from the ARDA. We then construct two new variables: Mainline Ratio and Evangelical Ratio. Mainline (Evangelical) Ratio is calculated as the fraction of the population in a particular county that is affiliated with Mainline (Evangelical) Protestant churches. We use these two additional religiosity ratios to study whether annuity writers are less likely to be headquartered in high Mainline (Evangelical) Ratio areas, and whether local Mainline (Evangelical) belief affects insurers' risktaking behaviour. Table OA7 in the Supplementary Material shows that annuity writers are less common in both high Mainline Ratio and high Evangelical Ratio areas. The magnitude of the coefficient on Evangelical Ratio is smaller than that Mainline Ratio (-3.968 vs. - 7.966). With regard to whether Mainline (Evangelical) belief affects insurers' risk-taking decisions, as reported in Tables OA8, OA9 and OA10 in the Supplementary Material, for annuity writers, Evangelical Ratio is significantly negatively related to asset risk, investment risk and total risk, while Mainline Ratio is insignificant. The coefficient magnitude of Evangelical Ratio is larger than Protestant Ratio in both cases. Overall, the effect of Evangelical Ratio on insurers' risk-taking behaviour is stronger than the effect of Mainline Ratio. In other words, the effects of local Protestant belief are mainly driven by Evangelical belief.

\section{Robustness checks}

Some insurance companies are affiliated with certain religious groups and use a targeted marketing strategy to focus on certain religious clientele with organisation memberships. In order to ensure our results are not driven by this specific type of insurer, we examine all 202 insurance companies in our sample and identify 12 insurers with religious words in their names. First, we drop these 12 firms or 49 observations from our sample and re-estimate all regressions. We present the findings in Tables OA11, OA12 and OA13 in the Supplementary Material. Overall, the results are qualitatively the same as in our baseline model, if not stronger. Alternatively, we code a dummy variable (Targeted Religious Clientele) that is equal to 1 for these 12 firms and 0 otherwise. We add Targeted Religious Clientele to the baseline model and re-estimate all regressions. We report the findings in Tables OA14, OA15 and OA16 in the Supplementary Material. Our results are robust to adding this dummy variable.

According to Jones et al. (2013), the majority of Hispanics are Catholics. To control for the impact of the Hispanic population on insurer risk-taking behaviour, we collect the fraction of Hispanics in the county population from the U.S. Census database and construct the Hispanic county demographic control variable. We add 
Hispanic as an additional control variable in all regression models. We present our findings in Tables OA17, OA18 and OA19 in the Supplementary Material. Overall, the results are stronger, with more religiosity ratios that are significant and have higher significance levels.

We use three alternative control variables for the stringency of regulation and reperform the analysis for each one of them separately. ${ }^{21}$ Next, we include the average life expectancy of the state in which an insurer is headquartered as an additional control variable for annuity demand and reperform the analysis. We also drop the financial crisis year 2008 from the sample and reperform the analysis. Further, we use an alternative method and estimate Fama-MacBeth regressions on the annuity writer indicator, and the results are reported in Tables OA20 and OA21 in the Supplementary Material. Our dataset includes stock, mutual and fraternal life insurance companies. The fraternal organisation is a unique organisational form for life insurance companies that has a number of similarities with the mutual organisational form. As a robustness check, we drop the mutual indicator variable from the model and re-run the analysis. We also use A.M. Best's financial strength ratings, convert the letter ratings to numerical ratings on a scale from 1 to 13 and use this variable as an alternative (inverse) measure of total risk in an ordered probit regression. Our main results are robust to these alternative model specifications and estimation methods.

Lastly, we replace the measure of religious beliefs with a measure of overall religiosity in a county and we reperform the analysis. This measure is calculated as the total number of individuals affiliated with any religion relative to the total population of a county. According to the results in Kumar et al. (2011), the overall religiosity ratio seems to be correlated with the fraction of Catholics in a county and seems to proxy for the effect of the catholic ratio on the dependent variable. In their study, the overall religiosity ratio is insignificant in many regressions; if it is significant, it has the same sign as the catholic ratio or the Catholic-to-Protestant ratio. We use overall religiosity ratio as the key independent variable and firms' overall risk (either Total Risk or A.M. Rating) as the dependent variable. We find that the signs of overall religiosity ratio are the same as those of the Catholic ratio or the Catholicto-Protestant ratio but the coefficients are insignificant, consistent with the findings in Kumar et al. (2011).

\footnotetext{
21 First, we code indicator variables for stringent form regulation in personal lines and stringent form regulation in commercial lines based on Tables A.1 and A.2 in Leverty and Liu (2019). We use the sum of those two indicators as a measure of regulatory stringency. Second, we use a measure for the stringency of regulation with respect to insurance companies' investments. This measure is from Appendix $\mathrm{C}$ in Boyer et al. (2020) and captures the number of investment categories that are subject to stringent regulation in a particular state. The measure takes on values between 0 and 14 . Third, we use an indicator of whether state regulation requires life insurance companies to report the value of their investments in statutory filings based on the stringent mark-to-market rule. This variable is from the baseline classification of Appendix C in Ellul et al. (2015).
} 


\section{Conclusions}

There is an increasing interest in academia in the behavioural and cultural aspects of business decisions. The goal of this study is to investigate whether local culture influences insurance companies' risk-taking. To answer this question, we focus on local religious beliefs for which we can obtain a quantifiable measure.

Using a sample of U.S. single unaffiliated life insurance companies from 2001 to 2010, we study the impact of county-level Catholic or Protestant ratios, measured by the share of Catholic or Protestant adherents to the total population of a county, on the risk-taking decisions of insurers headquartered in that county. First, we find that insurers that predominantly write annuities, which are arguably riskier than life insurance contracts, are more common in regions with a larger Catholic or a smaller Protestant population. We then employ three different risk measures to capture insurers' risk-taking activities. In recognition of the systematic difference in risks taken between the insurers that predominately write annuity business and those that predominately write life business, we separate the analyses on asset risk, investment risk and total risk-taking decisions for them. We document that annuity writers located in high Catholic-to-Protestant ratio, high-Catholic ratio or low-Protestant ratio counties take more asset risk and more total risk. We also find that annuity writers' investment risk is negatively related to their headquarter county's Protestant ratio. Overall, our results indicate that, despite the stringent regulation, intense competition and strong market discipline within the insurance industry, the effects of local culture on insurance company outcomes are not negligible.

Our study provides the first evidence that local religious beliefs, an important aspect of local culture, noticeably affect insurers' behaviour. This result should be of interest to policymakers, regulators and researchers. Of course, religious beliefs are only one part of local culture. Especially in international studies across different countries and continents, other cultural differences may be more pronounced than differences in religious beliefs. Whether the differences between life insurance companies headquartered in Catholic versus Protestant counties we observe in the U.S. exist in the same way in other countries is a question for future research. It is also beyond the scope of our research to examine whether the religious beliefs of the CEO influence life insurance companies' decisions beyond the influence of local religious beliefs. Our results simply provide evidence that local culture influences life insurance companies' decisions and especially their risk-taking decisions. Other interesting questions are left for future research.

\section{Appendix: Definitions of variables}

\begin{tabular}{ll}
\hline Variable & Definition \\
\hline Catholic Ratio & $\begin{array}{l}\text { Total number of Catholic adherents of a county divided by the county's } \\
\text { total population }\end{array}$ \\
\hline
\end{tabular}


Variable

Protestant Ratio

Catholic-to-Protestant Ratio

Asset Risk

Investment Risk

Total Risk

Firm Size

Capital-to-Assets Ratio

Net Premium Growth

Reinsurance Use

Geographic HHI

Mutual

Stock

Annuity Writer

Life Writer

Publicly Traded

Number of Licences

Annuity Bus. Fraction

Ordinary Annuity Bus. Fraction

Group Annuity Bus. Fraction

Life Bus. Fraction

A\&H Bus. Fraction

Other Bus. Fraction

Industrial Life Bus. Fraction

Ordinary Life Bus. Fraction

Supplemental Bus. Fraction

Credit Life Bus. Fraction

Group Life Bus. Fraction

Group A\&H Bus. Fraction

A\&H Credit Bus. Fraction
Definition

Total number of Protestant adherents of a county divided by the county's total population

Ratio of Catholics to Protestants of a county

Ratio of investments in equity securities and real estate to cash and total investments

Standard deviations of firm's ratio of investment income plus realised capital gains to the total invested net admitted assets (ROI) for the past four years

Standard deviations of firm's ratio of net income to the total net admitted assets (ROA) for the past four years

Natural logarithm of total net admitted assets

Fraction of total capital and surplus to total net admitted assets

Change of net premiums written (NPW) from previous year divided by previous year's NPW

Percentage of reinsurance ceded to the sum of direct premiums written and reinsurance assumed

$\Sigma\left(D B_{i} / T D B\right)^{2}$, where $D B_{i}$ is the value of total direct premiums and annuity considerations in state $i$, and TDB is the insurer's total direct premiums and annuity considerations across the U.S

Dummy equal to 1 if insurer is organised as a mutual company, and 0 otherwise

Dummy equal to 1 if insurer is organised as a stock company, and 0 otherwise

Indicator equal to 1 if insurer has over $2 / 3$ of NPW in ordinary individual annuity and group annuity, and 0 otherwise

Indicator equal to 1 if insurer has over $2 / 3$ of NPW in industrial life, ordinary life, group life and credit life, and 0 otherwise

Dummy equal to 1 if insurer is publicly traded, and 0 otherwise

Number of states an insurer is licenced to conduct business in

Indicator equal to 1 if insurer is licenced to conduct business in the State of New York, and 0 otherwise

Proportion of NPW in ordinary individual annuity and group annuity

Share of NPW in ordinary individual annuity

Share of NPW in group annuity

Share of NPW in industrial life, ordinary life, group life and credit life

Proportion of NPW in group Accident \& Health (A\&H), A\&H credit and $\mathrm{A} \& \mathrm{H}$ other insurance

Share of insurer's NPW in ordinary supplementary contracts and aggregate of all other lines besides ordinary, group, Accident \& Health, industrial life and credit life

Proportion of NPW in industrial life insurance

Proportion of NPW in ordinary life insurance

Proportion of NPW in ordinary supplementary contracts

Proportion of NPW in credit life insurance

Proportion of NPW in group life insurance

Proportion of NPW in group A\&H insurance

Proportion of NPW in A\&H credit insurance 


\begin{tabular}{|c|c|}
\hline Variable & Definition \\
\hline A\&H Other Bus. Fraction & Proportion of NPW in A\&H other insurance \\
\hline Other Fraction & $\begin{array}{l}\text { Proportion of NPW in all other lines than industrial life, ordinary life, } \\
\text { ordinary supplementary contracts, credit life, group life, group A\&H } \\
\text { and A\&H credit }\end{array}$ \\
\hline Group Bus. Fraction & Share of NPW in group life, group annuity and A\&H group insurance \\
\hline Firm Age & Number years since incorporation \\
\hline Population Age & Median age of the county population \\
\hline Education & $\begin{array}{l}\text { Percentage of highly educated people (bachelor's degree or higher) } \\
\text { among the population aged } 25 \text { years or older in a county }\end{array}$ \\
\hline Income & Per capita personal income in USD thousand in a county \\
\hline Population & County's total population in millions \\
\hline Minority & $\begin{array}{l}\text { Percentage of the minority population that is not White alone, non- } \\
\text { Hispanic in a county }\end{array}$ \\
\hline Married & $\begin{array}{l}\text { Percentage of married households to the total number of households in } \\
\text { a county }\end{array}$ \\
\hline MaletoFemale & Percentage of the male population to the female population in a county \\
\hline Population Density & Total population of a county in thousands divided by the county's area \\
\hline Dependency Ratio & $\begin{array}{l}\text { Number of dependents aged } 0-18 \text { and over the age of } 65 \text { divided by the } \\
\text { total population aged } 19-64 \text { in a state }\end{array}$ \\
\hline
\end{tabular}

Supplementary Information The online version contains supplementary material available at https://doi. org/10.1057/s41288-021-00211-z.

\section{Compliance with ethical standards}

Conflict of interest On behalf of all authors, the corresponding author states that there is no conflict of interest.

\section{References}

Adhikari, B.K., and A. Agrawal. 2016. Does local religiosity matter for bank risk-taking? Journal of Corporate Finance 38: 272-293.

Barro, R.J., and R.M. McCleary. 2003. Religion and economic growth across countries. American Sociological Review 68: 760-781.

Baker, M., B. Bradley, and J. Wurgler. 2011. Benchmarking as limits to arbitrage: Understanding the low volatility anomaly. Financial Analyst Journal 67: 40-54.

Barinov, A., J. Xu, and S.W. Pottier. 2020. Estimating the cost of equity capital for insurance firms with multi-period asset pricing models. Journal of Risk and Insurance 87: 213-245.

Barsky, R.B., F.T. Juster, M.S. Kimball, and M.D. Shapiro. 1997. Preference parameters and behavioral heterogeneity: An experimental approach in the health and retirement study. Quarterly Journal of Economics 112: 537-579.

Bell, R.C. 1974. Moral views on gambling promulgated by major American religious bodies. Commission on the Review of the National Policy Toward Gambling.

Benjamin, D.J., J.J. Choi, and G. Fisher. 2016. Religious identity and economic behavior. Review of Economics and Statistics 98: 617-637. 
Berger, A.N., J.D. Cummins, M.A. Weiss, and H. Zi. 2000. Conglomeration versus strategic focus: Evidence from the insurance industry. Journal of Financial Intermediation 9: 323-362.

Bernheim, B.D. 1991. How strong are bequest motives? Evidence based on estimates of the demand for life insurance and annuities. Journal of Political Economy 99 (5): 899-927.

Berry, F.S., and W.D. Berry. 1990. State lottery adoptions as policy innovations: An event history analysis. American Political Science Review 84: 395-415.

Berry-Stölzle, T.R., G.P. Nini, and S. Wende. 2014. External financing in the life insurance industry: Evidence from the financial crisis. Journal of Risk and Insurance 81: 529-562.

Berry-Stölzle, T.R., and J. Xu. 2018. Enterprise risk management and the cost of capital. Journal of Risk and Insurance 85 (1): 159-201.

Boyer, M.M., E.P. Cowins, and W.D. Reddic. 2020. Operational risk management and regulatory investment constraints on portfolio allocation. Journal or Regulatory Economics 57: 20-52.

Cai, J. 2019. Do religious norms influence corporate debt financing? Journal of Business Ethics 157: $159-182$.

Che, X., and J. Xu. 2020. Gender differences in reserving conservatism: Evidence from the U.S. property-liability insurance industry. California State University Working Paper.

Cummins, J.D., and P.M. Danzon. 1997. Price, financial quality, and capital flows in insurance markets. Journal of Financial Intermediation 6: 3-38.

Cummins, J.D., and S.E. Harrington. 1988. The relationship between risk and return: Evidence for property-liability insurance stocks. Journal of Risk and Insurance 55: 15-31.

Cummins, J.D., S.E. Harrington, and R. Klein. 1995. Insolvency experience, risk-based capital, and prompt corrective action in property-liability insurance. Journal of Banking and Finance 19: 511-527.

Doherty, N.A., and H. Schlesinger. 1990. Rational insurance purchasing: Consideration of contract nonperformance. Quarterly Journal of Economics 105: 243-253.

Doran, J.S., D. Jiang, and D.R. Peterson. 2012. Gambling preference and the new year effect of assets with lottery features. Review of Finance 16: 685-731.

Dyreng, S.D., W.J. Mayew, and W.D. Williams. 2010. Religious social norms and corporate financial reporting. Journal of Business Finance and Accounting 39: 845-875.

Eling, M., and J.T. Schmit. 2012. Is there market discipline in the European insurance industry? An analysis of the German insurance market. The Geneva Risk and Insurance Review 37: 180-207.

Ellison, C.G., and K.A. Nybroten. 1999. Conservative Protestantism and opposition to state-sponsored lotteries: Evidence from the 1997 Texas poll. Social Science Quarterly 80: 356-369.

Ellul, A., C. Jotikasthira, C.T. Lundblad, and Y. Wang. 2015. Is historical cost accounting a panacea? Market stress, incentive distortion, and gains trading. Journal of Finance 70 (6): 2489-2537.

Epermanis, K., and S.E. Harrington. 2006. Market discipline in property/casualty insurance: Evidence from premium growth surrounding changes in financial strength ratings. Journal of Money, Credit, and Banking 38: 1515-1544.

Fields, L.P., M. Gupta, and P. Prakash. 2012. Risk taking and performance of public insurer: An international comparison. Journal of Risk and Insurance 79: 931-962.

Gao, L., Y. Wang, and J. Zhao. 2017. Does local religiosity affect organizational risk-taking? Evidence from the hedge fund industry. Journal of Corporate Finance 47: 1-22.

Gaver, J.J., and S.W. Pottier. 2005. The role of holding company financial information in the insurerrating process: Evidence from the property-liability industry. Journal of Risk and Insurance 72: 77-103.

Grullon, G., G. Kanatas, and J. Weston. 2010. Religion and corporate (mis)behavior. Rice University Working Paper.

Guiso, L., P. Sapienza, and L. Zingales. 2006. Does culture affect economic outcomes? Journal of Economic Perspectives 20: 23-48.

Halek, M., and J.G. Eisenhauer. 2001. Demography of risk aversion. Journal of Risk and Insurance 68: $1-24$.

Hilary, G., and K.W. Hui. 2009. Does religion matter in corporate decision making in America? Journal of Financial Economics 93: 455-473.

Ho, C., G.C. Lai, and J. Lee. 2013. Organizational structure, board composition, and risk taking in the U.S. property casualty insurance industry. Journal of Risk and Insurance 80: 169-203.

Hoffman, J.P. 2000. Religion and problem gambling in the U.S. Review of Religious Research 41: 488-509. 
Hofstede, G. 1984. Culture's consequences: International differences in work-related values. Beverly Hills, CA: Sage.

Holland, J. 1976. Vocational preferences. In Handbook of industrial and organizational psychology, ed. M. Dunnette, 521-570. Chicago: Rand McNally.

Iannaccone, L.R. 1998. Introduction to the economics of religion. Journal of Economic Literature 36: 1465-1496.

Jia, R., S. Liu, J. Wang, and J. Xu. 2020. Regulatory inconsistency and shadow insurance: The impact of Solvency II on the U.S. insurance market. Peking University Working Paper.

Jones, R.P., D. Cox, and J. Navarro-Rivera. 2013. Hispanic values survey: How shifting religious identities and experiences are influencing Hispanic approaches to politics. Washington, DC: Public Religion Research Institute.

Kumar, A. 2009. Who gambles in the stock market? Journal of Finance 64: 1889-1933.

Kumar, A., J. Page, and O. Spalt. 2011. Religious beliefs, gambling attitudes, and financial market outcomes. Journal of Financial Economics 102: 671-708.

Lamm-Tennant, J., and L.T. Starks. 1993. Stock versus mutual ownership structures: The risk implication. Journal of Business 66: 29-46.

La Porta, R., F. Lopez-de-Silanes, A. Shleifer, and R. Vishny. 1999. The quality of government. Journal of Law, Economics, and Organization 15: 222-279.

Lee, S.J., D. Mayers, and C.W. Smith. 1997. Guaranty funds and risk-taking: Evidence from the insurance industry. Journal of Financial Economics 44: 3-24.

Leverty, T., and J. Liu. 2019. Does technology adoption save regulatory compliance costs? University of Wisconsin-Madison Working Paper.

L'Haridon, O., and F.M. Vieider. 2019. All over the map: A worldwide comparison of risk preferences. Quantitative Economics 10: 185-215.

Ma, L., M. Zhang, J. Gao, and T. Ye. 2020. The effect of religion on accounting conservatism. European Accounting Review 29 (2): 383-407.

Mankaï, S., and A. Belgacem. 2016. Interactions between risk taking, capital, and reinsurance for property-liability insurance firms. Journal of Risk and Insurance 83: 1007-1043.

Mayers, D., and C.W. Smith Jr. 1986. Ownership structure and control: Mutualization of stock life insurance companies. Journal of Financial Economics 16: 73-99.

McGuire, S.T., T.C. Omer, and N.Y. Sharp. 2012. The impact of religion on financial reporting irregularities. Accounting Review 87 (2): 645-673.

Milidonis, A., T. Nishikawa, and J. Shim. 2019. CEO inside debt and risk taking: Evidence from property-liability insurance firms. Journal of Risk and Insurance 86: 451-477.

Noussair, C.N., S.T. Trautmann, G. van de Kuilen, and N. Vellekoop. 2013. Risk aversion and religion. Journal of Risk and Uncertainty 47: 165-183.

Pope, B., J. Price, and D.R. Lillard. 2014. The impact of religion on youth outcomes. Journal of Business Inquiry 13: 48-60.

Pottier, S.W. 2007. The determinants of private debt holdings: Evidence from the life insurance industry. Journal of Risk and Insurance 74 (3): 591-612.

Pottier, S.W., and D.W. Sommer. 1998. Regulatory stringency and New York licensed life insurers. Journal of Risk and Insurance 65: 485-502.

Schneider, B. 1987. The people make the place. Personnel Psychology 40: 437-453.

Schneider, B., H. Goldstein, and D. Smith. 1995. The ASA framework: An update. Personnel Psychology 48: 747-773.

Schneider, C., and O. Spalt. 2016. Conglomerate investment, skewness, and the CEO long shot bias. Journal of Finance 71: 635-671.

Schneider, C., and O. Spalt. 2017. Acquisitions as lotteries? The selection of target-firm risk and its impact on merger outcomes. Critical Finance Review 6: 77-132.

Shu, T., J. Sulaeman, and P.E. Yeung. 2012. Local religion beliefs and mutual fund risk-taking behaviors. Management Science 58: 1779-1796.

Starkey, L.M. 1964. MONEY, MANIA, AND MORALS: THE CHURCHES AND GAMBLING. New York: Abingdon Press.

Stulz, R.M., and R. Williamson. 2003. Culture, openness, and finance. Journal of Financial Economics 70: 313-349.

Tajfel, H. 1978. DIFFERENTIATION BETWEEN SOCIAL GROUPS: STUDIES IN THE SOCIAL PSYCHOLOGY OF INTERGROUP RELATIONS. London: Academic Press.

Tec, N. 1964. Gambling in Sweden. Totowa, NJ: Bedminster Press. 
Turner, J.C., and K.J. Reynolds. 2010. The story of social identity. Rediscovering social identity: Core sources. East Sussex: Psychology Press.

Vroom, V. 1966. Organizational choice: A study of pre- and post-decision processes. Organizational Behavior and Human Performance 1: 212-226.

Publisher's Note Springer Nature remains neutral with regard to jurisdictional claims in published maps and institutional affiliations.

\section{About the authors}

Thomas R. Berry-Stölzle is Associate Professor of Finance, Nationwide Faculty Fellow, and Faculty Director of the Vaughan Institute of Risk Management and Insurance at Henry B. Tippie College of Business, University of Iowa, USA

Jianren Xu is Assistant Professor in the Department of Finance, Insurance, Real Estate and Law at G. Brint Ryan College of Business, University of North Texas, USA. 